\title{
Low Emission Hydrogen Combustors for Gas Turbines Using Lean Direct Injection
}

\author{
C. John Marek, ${ }^{*}$ Timothy D. Smith, ${ }^{\dagger}$ and Krishna Kundu ${ }^{*}$ \\ NASA Glenn Research Center, Cleveland, Ohio 44135
}

\begin{abstract}
One of the key technology challenges for the use of hydrogen in gas turbine engines is the performance of the combustion system, in particular the fuel injectors. To investigate the combustion performance of gaseous hydrogen fuel injectors flame tube combustor experiments were performed. Tests were conducted to measure the nitrogen oxide $\left(\mathrm{NO}_{\mathbf{x}}\right)$ emissions and combustion performance at inlet conditions of 600 to $1000{ }^{\circ} \mathrm{F}, 60$ to 200 psia, and equivalence ratios up to 0.48. All the injectors were based on Lean Direct Injection (LDI) technology with multiple injection points and quick mixing. One challenge to hydrogen based premixing combustion systems is flashback since hydrogen has a reaction rate over seven times that of Jet-A. To reduce the risk, design mixing times were kept short and velocities high to minimize flashback. Five fuel injector designs were tested in $\mathbf{2 . 5}$ and 3.5-in. diameter flame tubes with non-vitiated heated air and gaseous hydrogen. Data is presented on measurements of $\mathrm{NO}_{\mathrm{x}}$ emissions and combustion efficiency for the hydrogen injectors at 1.0, 3.125, and 5.375 in. from the injector face. Results show that for some configurations, $\mathrm{NO}_{\mathrm{x}}$ emissions are comparable to that of state of the art Jet-A LDI combustor concepts.
\end{abstract}

\begin{tabular}{|c|c|c|}
\hline & & Nomenclature \\
\hline$A, a, b, c, d, e$ & $=$ & correlation constants for emission index based on hydrogen data \\
\hline$A$ & $=$ & correlation constant for emission index based on Jet-A fuel \\
\hline$A C D$ & $=$ & effective fuel injector flow area $\left(\mathrm{in}^{2}\right)$ \\
\hline$E I N O_{x}$ & $=$ & nitrogen oxide emission index, $\mathrm{gm} \mathrm{NO}_{\mathrm{x}} / 1000 \mathrm{gm}$ fuel \\
\hline f/a & $=$ & fuel to air ratio \\
\hline$\dot{m}_{a}$ & $=$ & air mass flow $\left(\mathrm{lb}_{\mathrm{m}} / \mathrm{s}\right)$ \\
\hline$K$ & $=$ & calibration constant for the inferential temperature probe \\
\hline$g_{c}$ & $=$ & proportionality constant $\left(32.2 \mathrm{lb}_{\mathrm{m}}-\mathrm{ft} / \mathrm{lb}_{\mathrm{f}}-\mathrm{s}^{2}\right)$ \\
\hline$P_{3}$ & $=$ & fuel injector inlet air pressure (psia) \\
\hline$R_{2}$ & $=$ & correlation coefficient, sum of error in Eq. (12) \\
\hline$T_{3}$ & $=$ & fuel injector inlet air temperature $\left({ }^{\circ} \mathrm{F}\right)$ \\
\hline$T_{4}$ & $=$ & combustor exit temperature $\left({ }^{\circ} \mathrm{F}\right)$ \\
\hline$T_{\text {probe }}$ & $=$ & inferential probe temperature $\left({ }^{\circ} \mathrm{F}\right)$ \\
\hline$T_{\text {water }}$ & $=$ & cooling water temperature $\left({ }^{\circ} \mathrm{F}\right)$ for the inferential probe \\
\hline$\tau$ & $=$ & residence time $(\mathrm{ms})$ \\
\hline$V_{\text {ref }}$ & $=$ & air flow inlet reference velocity ( $\mathrm{ft} / \mathrm{s}$ ) at combustor inlet conditions \\
\hline$X$ & $=$ & downstream distance from the face of the injector, inches \\
\hline$\Delta p$ & $=$ & fuel injector air flow pressure drop (psid) \\
\hline$\Delta p / p$ & $=$ & fuel injector air flow pressure drop ratio (percent) \\
\hline$\varphi$ & $=$ & equivalence ratio $[(f / a) /(f / a)$ stociometric $]$ \\
\hline$\rho_{3}$ & $=$ & fuel injector inlet air density $\left(\mathrm{lb}_{\mathrm{m}} / \mathrm{ft}^{3}\right)$ \\
\hline
\end{tabular}

*Aerospace Engineer, 21000 Brookpark Road

${ }^{\dagger}$ Glenn Project Manager, 21000 Brookpark Road, Senior Member AIAA

${ }^{\ddagger}$ Chemical Engineer, 21000 Brookpark Road

Copyright (c) 2005 by the American Institute of Aeronautics and Astronautics, Inc. The U.S. Government has a royalty-free license to exercise all rights under the copyright claimed herein for Governmental purposes. All other rights are reserved by the copyright owner. 


\section{Background}

$\mathrm{W}$ ITH the push towards the use of alternative energy, a hydrogen based energy economy is again of interest. There is an increasing urgency to find alternative sources of energy as petroleum reserves decrease while at the same time world tension increases. As the development of a hydrogen economy progresses into other forms of transportation, it is reasonable to expect that eventually hydrogen based systems will become an emerging technology for future aircraft propulsion. This would not be an entirely new development. The concept of hydrogen powered gas turbine aircraft has been around for over half a century. A number of hydrogen based propulsion systems and aircraft concepts have been evaluated over the years for both subsonic and supersonic flight. A detailed account on many of these projects can be found in the excellent compilation by Brewer. ${ }^{1}$ The earliest flight of a hydrogen based aircraft was in 1956, when one engine of a B-57 was flown with hydrogen by the NACA Lewis Flight Propulsion Laboratory, today known as NASA Glenn Research Center. Other work in that era include project Suntan, ${ }^{2}$ a Mach 2.5 reconnaissance aircraft that was being developed by Lockheed Skunk Works for the Air Force. Although the project was cancelled in 1959, advances were made in propulsion system development with testing of the Pratt \& Whitney 304 engine. While the promise of hydrogen gas turbine aircraft was never realized in the 1950's the lessons learned provided a critical stepping stone to the use of hydrogen in the Space Program.

One key difference from previous hydrogen based systems is the requirement today to address the ever increasing environmental emissions regulations. The use of hydrogen as an aircraft fuel has tremendous environmental benefits over current systems with the elimination of carbon monoxide $(\mathrm{CO})$, carbon dioxide $\left(\mathrm{CO}_{2}\right)$, sulfur oxides $\left(\mathrm{SO}_{\mathrm{x}}\right)$, unburnt hydrocarbons $(\mathrm{UHC})$, and smoke. Emissions from hydrogen engines are relatively benign, comprising of water and nitrogen oxides $\left(\mathrm{NO}_{\mathrm{x}}\right)$, each of which has some environmental impacts, however overall significantly less than conventional engines of today. The impact of $\mathrm{NO}_{\mathrm{x}}$ as a greenhouse gas is well known and steps can be taken to minimize these emissions in hydrogen gas turbine engines. As a result, based on engine emissions, hydrogen provides an environmentally friendly option for use in future propulsion systems.

While $\mathrm{CO}, \mathrm{CO}_{2}, \mathrm{SO}_{\mathrm{x}}, \mathrm{UHC}$, and smoke all play a significant role in global climate change, for aircraft $\mathrm{NO}_{\mathrm{x}}$ may present the greatest concern. $\mathrm{NO}_{\mathrm{x}}$ is a collective term which refers to the combination of nitric oxide (NO) and nitrogen dioxide $\left(\mathrm{NO}_{2}\right)$. The chemical kinetics of hydrogen and nitrogen oxide formation rates are well known. ${ }^{3} \mathrm{NO}_{\mathrm{x}}$ production is highly dependant upon temperature (inlet air and combustion), residence time, mixedness, and engine pressure. An excellent discussion on the formation of $\mathrm{NO}_{\mathrm{x}}$ as related to gas turbine combustors can be found in Lefebvre. ${ }^{4}$ The author summarizes the body of work on $\mathrm{NO}_{\mathrm{x}}$ formation to show clearly that emission levels increase with inlet air temperature and longer combustor residence times. Fuel injector designs which provide high levels of mixing between the fuel and air have been a key to reducing $\mathrm{NO}_{\mathrm{x}}$ emissions. Results for pressure increase are inconclusive, in some cases there is an increase and in other studies, no effect.

As expected there has been a limited amount of related work on the formation of $\mathrm{NO}_{\mathrm{x}}$ in hydrogen fueled gas turbine engines. Some of the early work ${ }^{5}$ looked into emissions reducing designs using lean pre-mixed systems. Although those systems did show improvements in the $\mathrm{NO}_{\mathrm{x}}$ emissions, they were not very compact and would have led to increased engine sizes. Also, the pre-mixed systems were highly susceptible to flashback and unpredictable flameholding. More recently work ${ }^{6}$ was conducted in support of the European Cryoplane ${ }^{7}$ Program to examine lean premixed and micro-mixing designs. Results from that effort showed significant $\mathrm{NO}_{\mathrm{x}}$ reductions, up to one order of magnitude (from part per million ( $\mathrm{ppm}$ ) levels of 10+ with hydrocarbons to $<1$ with hydrogen), using micro-mixing and pre-mixed fuel injectors when tested at ambient pressure in auxiliary power units (APU). Additional work ${ }^{8,9}$ was conducted on aircraft gas turbine configurations in both flame tube and sector testing. As with the APU testing, $\mathrm{NO}_{\mathrm{x}}$ reductions can be accomplished by converting from hydrocarbon to hydrogen fuels.

To examine new fuel injector designs for potential hydrogen gas turbine engines, NASA initiated the Zero $\mathrm{CO}_{2}$ Engine Technology project. A complimentary effort to the experimental efforts included computational modeling with the National Combustor Code (NCC). ${ }^{10}$ Work was conducted to compare experimental results from Anderson ${ }^{8}$ with the numerical predictions. ${ }^{11}$ Once the comparison was completed, the code was used to perform preliminary modeling of fuel injector concepts. ${ }^{12}$ Work was also completed to examine the flame structure of a conceptual fuel nozzle at ambient conditions, ${ }^{13}$ where data was collected using advanced laser diagnostic techniques which could then be used with computer code development and validation efforts. To date, several concepts utilizing lean direct LDI, lean pre-mixed, and hybrid combinations have been designed and tested, results of which are present herein. Initial test results are encouraging; with $\mathrm{NO}_{\mathrm{x}}$ levels lower than some of the state of the art Jet-A systems.

\section{Test Facility}

Testing was conducted in cell 23 of the Research Combustion Laboratory (RCL-23) at NASA Glenn Research Center (GRC), which is just one of several combustor tests facilities at GRC. ${ }^{14}$ In combination, these facilities can accommodate a wide range of test conditions and hardware configurations. As part of this project, RCL-23 was 
updated and modified to accommodate gaseous hydrogen as a fuel. Details of the modification and a full description of the test facility can be found in Smith, et al. ${ }^{15}$

RCL-23 is a highly flexible test facility that can perform a variety of flametube combustion experiments. Continuous research airflow rates up to $3.0 \mathrm{lb}_{\mathrm{m}} / \mathrm{s}$ are possible with the 450 -psig supply system over a range of inlet temperatures. Research air is heated in a shell-in-tube heat exchanger, providing nonvitiated air up to $1100{ }^{\circ} \mathrm{F}$ depending upon air flowrate. The gaseous hydrogen is supplied from a 70,000 $\mathrm{stdft}^{3}$ tube trailer at flow rates up to $0.05 \mathrm{lb}_{\mathrm{m}} / \mathrm{s}$. Supply pressure can be regulated up to the trailer maximum supply of $2400 \mathrm{psig}$. Both a calibrated subsonic venturi and a coriolis-type mass flowmeter in series provide flow measurement. The two meters agreed to within two percent on hydrogen mass flow for all readings. The Table 1 below summarizes the current facility capabilities of RCL-23.

Table 1. NASA GRC RCL-23 facility test parameters

\begin{tabular}{|l|l|}
\hline Maximum continuous research airflow, $\mathrm{lb}_{\mathrm{m}} / \mathrm{s}$ & 3.0 \\
\hline Maximum hydrogen flow rate, $\mathrm{lb}_{\mathrm{m}} / \mathrm{s}$ & 0.05 \\
\hline Maximum nonvitiated research air temperature, ${ }^{\circ} \mathrm{F}$ & 1100 \\
\hline Maximum research air pressure, $\mathrm{psia}$ & 350 \\
\hline Maximum combustion temperature, ${ }^{\circ} \mathrm{F}$ & 3000 \\
\hline
\end{tabular}

The main facility research section consists of a variable length inlet pipe, fuel injector housing, combustor housing, an ignition system, a set of gas sample probes, and the gas analysis system; a total length of 100 in., running from the outlet of the heat exchanger to the water-cooled automatically controlled backpressure valve housing. The test cell can accommodate round or square fuel injector configurations as part of an interchangeable flange system. The combustion section and inlet pipes can be either actively cooled with water or passively cooled with internal ceramic liners, or both. The combustion temperature in the research housing is limited to $3000{ }^{\circ} \mathrm{F}$, which is the limit for survivability of the ceramic liners. Ignition was accomplished using a specially designed hydrogen-air torch igniter. Fig. 1 shows a cross-section of the facility research section with three gas sample probes installed.

A new water-cooled gas sample probe has been developed for use in hydrogen testing (Fig. 2).

The temperature probe is an inferential probe. The thermocouple is inserted through the probe for support into the hot gas stream. This allows for temperature measurements to be obtained at approximately the same location and time as the gas sample is drawn. The probes were traversed radially from the wall to the center. Data are reported for only the wall and center locations, (see Fig. 1). The probe locations were equations available, $(1.0,3.125$, and 5.375 in.) from the face of the injector. The unique feature is that the thermocouple is located at the downstream edge of the flat tip of the water cooled probe, so that it is within the boundary layer of the cooled tip. The hot gas temperature $T_{4}$ can be computed from:

$$
T_{4}=\frac{\left[\text { Tprobe }^{*}(1+K)-T_{\text {water }}\right]}{K}
$$

where $K$, calibration constant, is calibrated with preheat only to $T_{3}=1000^{\circ} \mathrm{F}$.

$$
K=\frac{\left(T_{3}-T_{\text {water }}\right)}{\left(T_{3}-T_{\text {probe }}\right)}
$$

One difficulty is that if the water flow was not high enough, the water temperature varied and this variable had to be accounted for. In all cases the hot gas temperature was almost equal to the equilibrium temperature for the burned mixture.

The gas sample acquisition system consists of the single gas sample probe, heated lines to transport the sample, and an actuation method for inserting the probes into the combustor

The probes draw 10 to $15 \mathrm{std}$ liter/min of sample from the combustion zone into the heated trace lines and to the gas analysis bench. The heated trace lines are kept at $300^{\circ} \mathrm{F}$ to prevent condensation of water in the sample. 


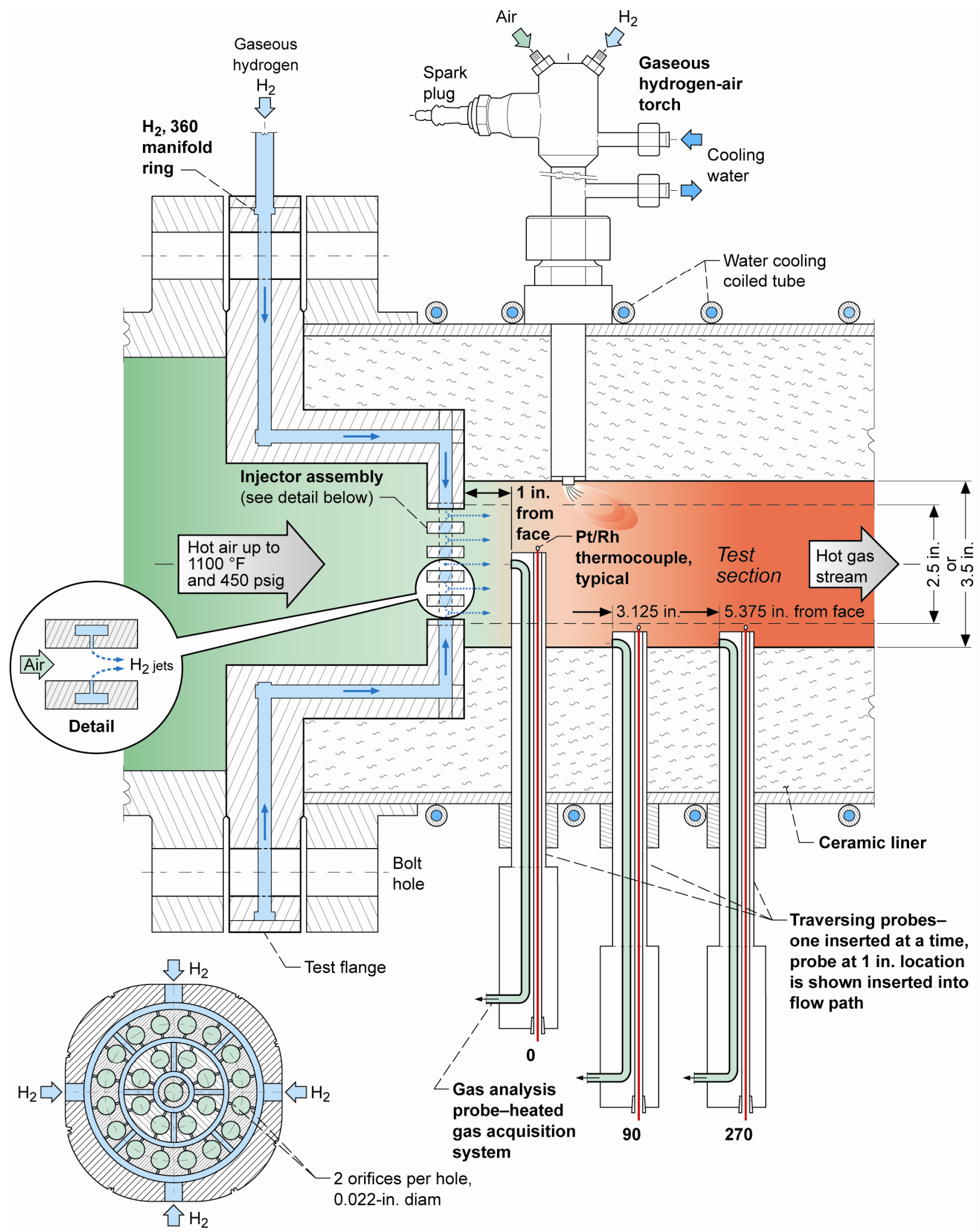

Injector assembly detail

25 air holes, 0.250-in. diam

Figure 1. Sketch of NASA low emissions LDI hydrogen combustor. 

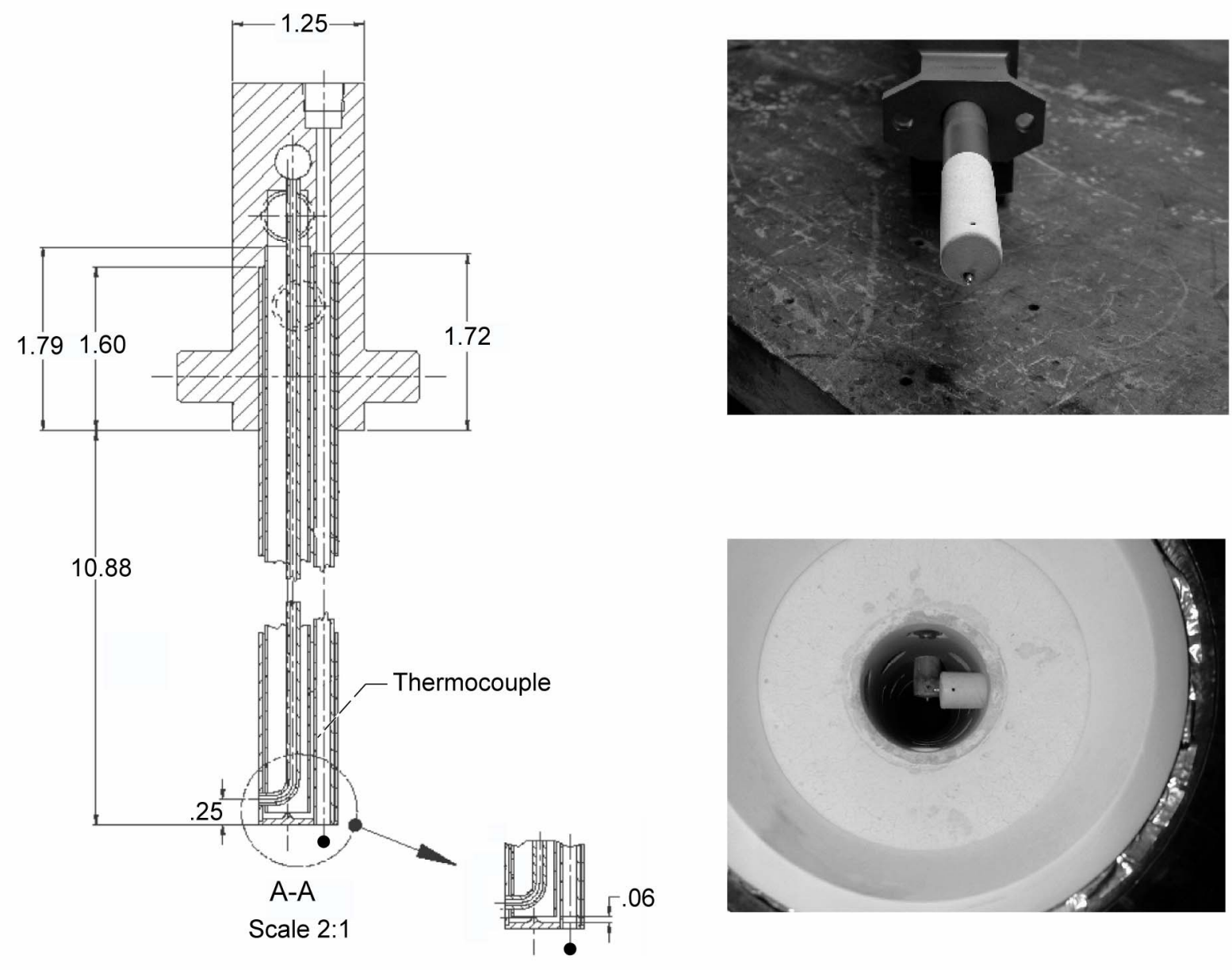

Figure 2. RCL-23 gas sample probe configuration with embedded thermocouple; dimensions are in inches.

\section{Test Hardware}

A total of five fuel injector configurations were tested as part of this effort. One of the designs was generated inhouse at NASA Glenn, while the four remaining designs were generated by major fuel injector manufacturers. The selected manufacturers had previously been testing configurations for either rocket injectors or low emission injectors for Jet-A fuel. This combination of designs serves as a baseline for future development. Photos of the downstream faces of the four injectors before testing are shown in Fig. 3.

A specified design criterion for all designs was a nominal air pressure drop $(\Delta P / P)$ of $4 \%$ at $100 \mathrm{ft} / \mathrm{s}$ reference velocity $\left(V_{\text {ref }}\right)$, which corresponds to approximately $72 \%$ blockage. NASA Glenn only requested the nominal $4 \%$ pressure drop from the manufactures. Some of the designs exceeded this value as shown later. The designs were tested anyway. Details of the manufacturer's configurations are proprietary and only the downstream faces are shown here with a brief description of the concepts. All of the configurations use some variation or combination of a lean direct injection (LDI) and lean pre-mixed pre-vaporized (LPP) schemes.

\section{Configurations}

The NASA GRC (N1), shown in Fig. 3(a), injector used two opposing hydrogen jets in the mixing tube. The jet penetration and mixing was designed using the jet in crossflow program. ${ }^{16}$ The result was a design that created a very short area of pre-mixing as the flow exited the main elements. In this configuration air flows through the 25 injection elements with side injection of gaseous hydrogen located at two positions 180 degrees apart. The air elements are 0.25 -in. diameter and the hydrogen injection holes are 0.020 in. in diameter. The NASA injector was fabricated with a simple method from three rings as shown in Fig. 4.

These rings could be drilled through from the outside and then seam welded together to form a hydrogen tight configuration, Fig. 5. 


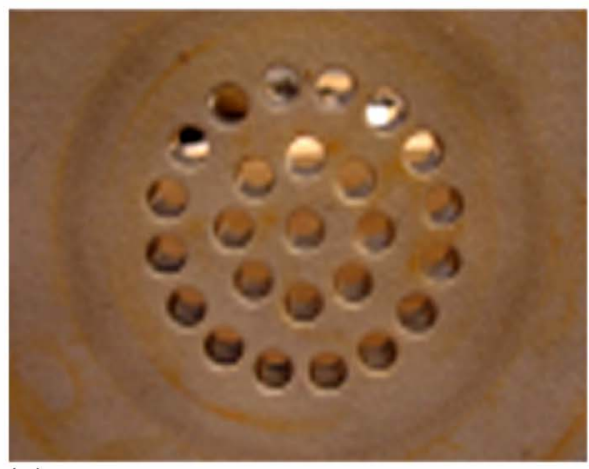

(a)

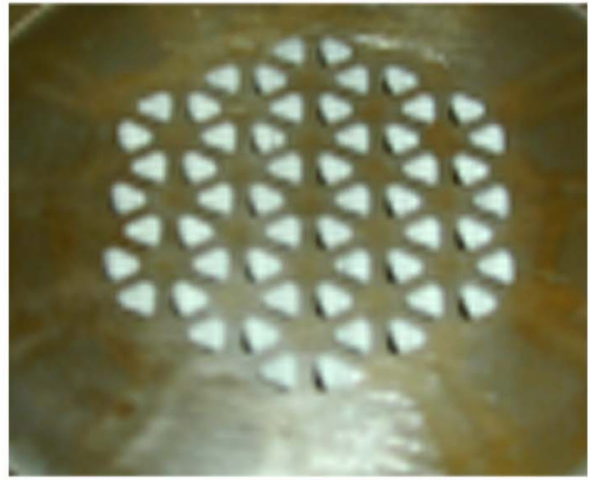

(c)

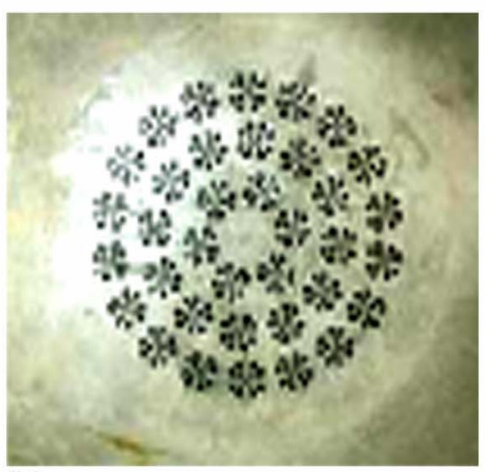

(b)

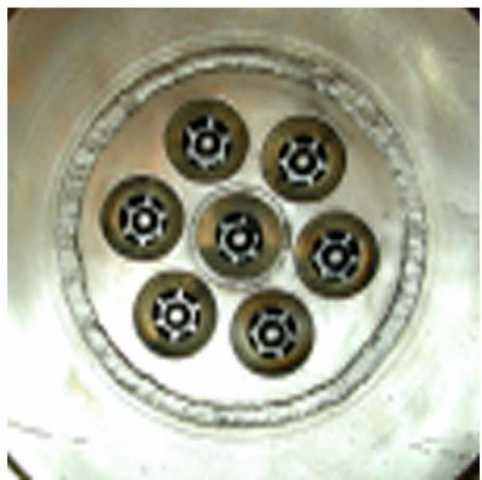

(d)

Figure 3. Four injectors tested. (a) NASA N1 injector. (b) Configuration C1. (c) Configuration C2. (d) Configuration C3 and Mod C4.

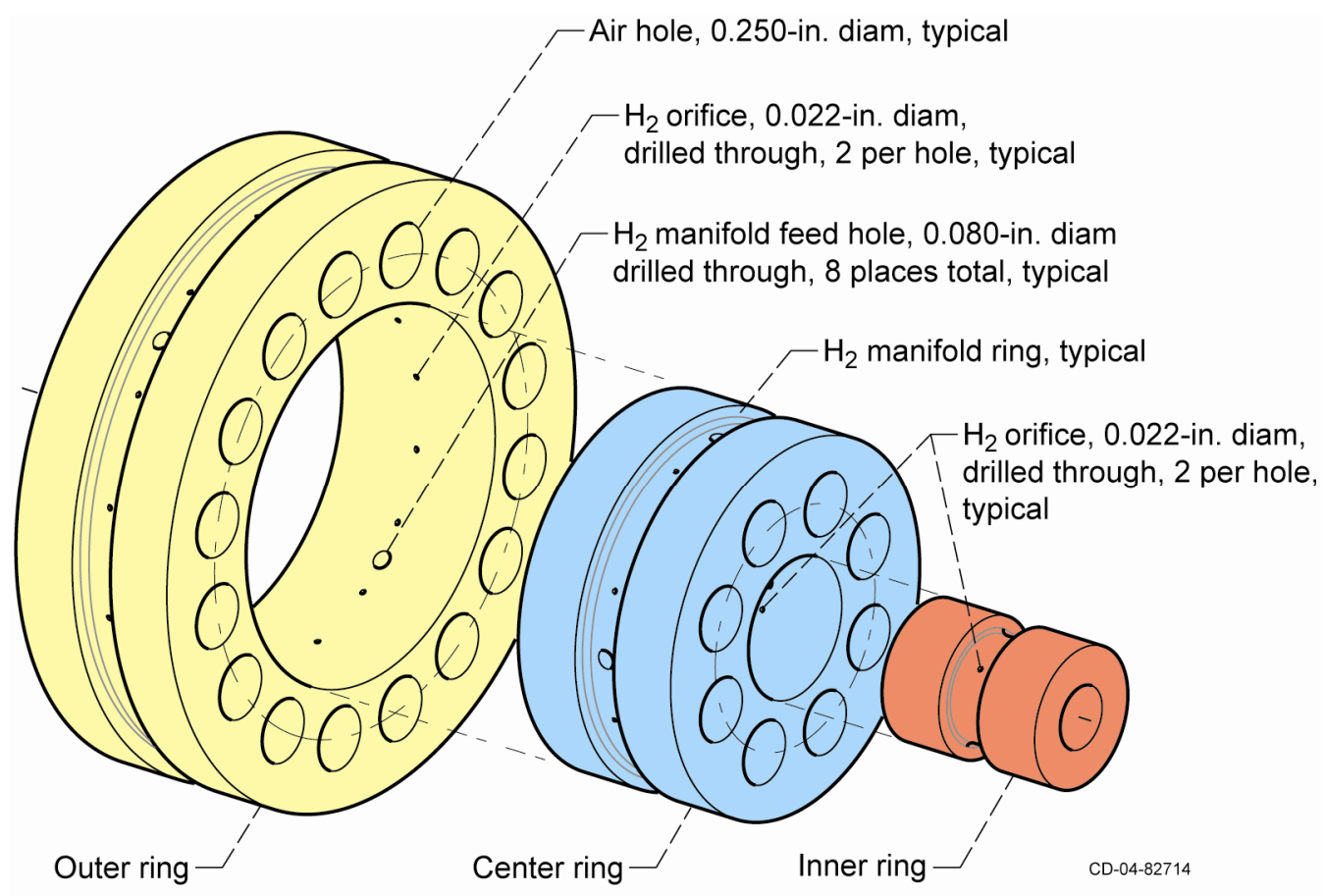

Figure 4. Three-piece injector brazing assembly detail-25 air holes total. 


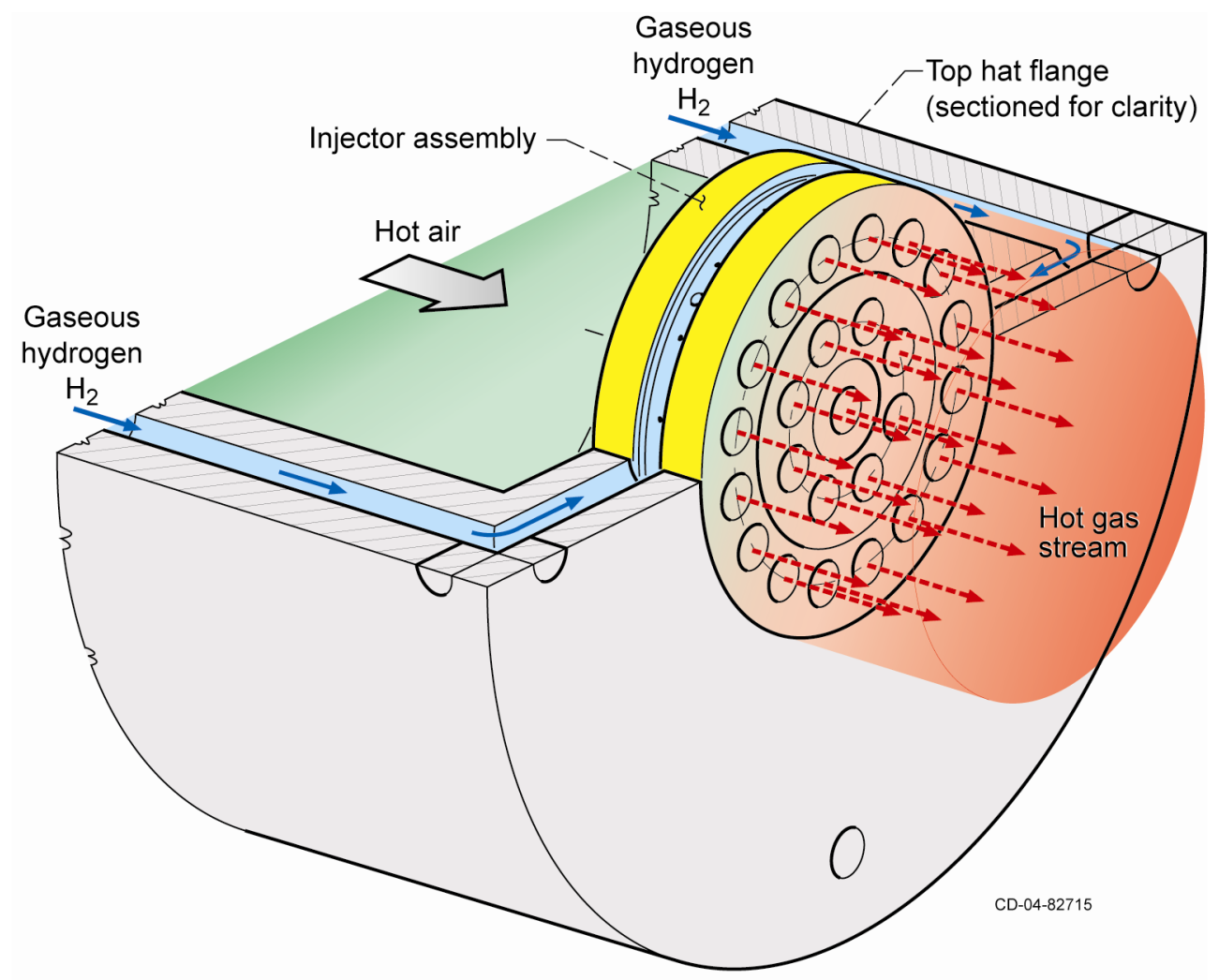

Figure 5. NASA low emissions LDI hydrogen combustor assembly.

Configuration C1, shown in Fig. 3(b), is based on previously demonstrated rocket injection technology with a center "+" hydrogen jet and eight angled air jets mixing with the hydrogen. For this concept a rich region was created near the face for ignition and flameholding using the four inner air jets of the air injection points. An immediate quench section was then created just down stream using the four remaining air injection points.

Configuration C2, shown in Fig. 3(c), is similar to the N1 injector design, but instead of circles used triangular holes with hydrogen normal injection on each edge of the triangle. The triangle injection concept was used to maximize packaging of the elements while keeping the airflow area consistent with N1. Reducing the size and increasing the number of injection elements, along with adding an additional hydrogen injection point per element, was intended to increase hydrogen penetration in the airflow stream and promote additional mixing. The unique manufacturing method utilized allowed for a greater number and distribution of hydrogen injection points.

Configuration C3, shown in Fig. 3(d), is a conservative design based on current gas turbine technology using a single center hydrogen nozzle at the center of each hole with a large amount of counter swirl to produce mixing.

Configuration $\mathrm{C} 4$ is based on $\mathrm{C} 3$, however the center hole is replaced by four small radial diameter hydrogen jets per injection point. For this configuration there is no air swirl.

The N1, C1, and C2 fuel injectors were tested in a 2.5-in. diameter ceramic combustor liner. Configurations C3 and $\mathrm{C} 4$ were tested in a 3.5-in. diameter liner and to baseline the data, configuration N1 was retested in the 3.5-in. diameter liner.

Table 2 provides a summary of the corrected pressure drop Eq. (2), and the effective flow area $(A C D)$, for the fuel nozzle designs tested. Equations (3) to (5) detail the calculation steps.

$\triangle P / P \%$ was corrected to $600{ }^{\circ} \mathrm{F}$ and $100 \mathrm{ft} / \mathrm{s}$ reference velocity for comparison-of the configurations, see Eq. (3). 
Table 2. Configuration design flow data

\begin{tabular}{|l|c|c|}
\hline Configuration & $\triangle P / P(\%)$ & $A C D$ \\
\hline NASA N1 2.5 in. liner & 4 & 1.30 \\
\hline Configuration C1 2.5 in. & 12 & 0.73 \\
\hline Configuration C2 2.5 in. & 4 & 1.26 \\
\hline Configuration C3 3.5 in. & 20 & 0.82 \\
\hline Configuration C4 3.5 in. & 25 & 0.97 \\
\hline NASA N1 3.5 in. liner & 16 & 1.27 \\
\hline
\end{tabular}

The pressure drop was corrected to $100 \mathrm{ft} / \mathrm{s}$ because all of the data could not be taken at this level. The pressure drop was normalized to $100 \mathrm{ft} / \mathrm{s}$ reference velocity so that all of the configurations can be compared at the same loading. The effective loss of a configuration is given by $A C D$ in inches. ${ }^{2}$

$$
A C D=\text { Area injector } * \mathrm{CD}=\frac{\dot{m}_{a}}{\sqrt{2 \rho_{3} g_{c} \Delta p_{a}}}
$$

$A C D$ is independent of velocity, temperature and pressure.

The pressure loss was corrected to the same reference velocity and inlet temperature with the relation:

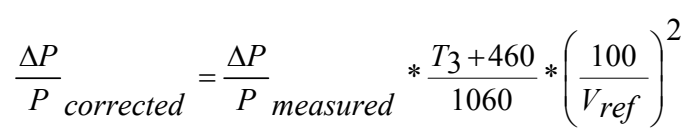

The reference velocity is given by the flow through the maximum area of the combustor at the combustor inlet conditions.

$$
V_{r e f}=\frac{\dot{m}_{a}}{\rho_{3} * A \max }
$$

\section{Experimental Results}

The test matrix consisted of approach $\left(620^{\circ} \mathrm{F}, \mathrm{P}=100\right.$ to $\left.150 \mathrm{psia}\right)$ cruise $\left(800{ }^{\circ} \mathrm{F}, P=100\right.$ to 150 psia $)$ and reduced takeoff $\left(980^{\circ} \mathrm{F}, \mathrm{P}=100\right.$ to $\left.150 \mathrm{psia}\right)$ over the complete equivalence ratio range $(0.1$ to 0.48$)$. Reference velocities ranged from 60 to $150 \mathrm{ft} / \mathrm{s}$. Lower velocities were chosen for configurations with higher pressure loss in order to keep the combustor velocity reasonable. In other words the inlet pressure $P_{3}$ and temperature $T_{3}$ were set. Then if the injector pressure drop were high, $P_{4}$ would be low with a resulting high combustor velocity. The ramp of fuel was stopped when the liner temperature exceeded $3000^{\circ} \mathrm{F}$ which was the material limit for our ceramic liners.

The nitrogen oxide data is presented as ppm wet at the same combustor exit temperature $\left(T_{4}\right)$ as in the Jet-A design, rather than emissions index (EI, gm NO $\mathrm{X}_{\mathrm{X}} / 1000 \mathrm{gm}$ fuel) because of the following difficulties. Hydrogen fuel is $1 / 3$ the weight of Jet-A per British thermal unit (BTU), so would have a higher EI at the same heat output, but would require less mass of fuel for the mission.

The relationship between the equilibrium $T_{4}$ and the fuel/air ratio for hydrogen and Jet-A is shown in Fig. 6 .

If the $f / a$ ratio of Jet-A is divided by 2.55 , in the region of interest from an $f / a_{\text {hydrogen }}$ from 0.0029 to 0.014 $\left(\varphi=0.1\right.$ at attempted light off to a maximum $T_{4}$ of $\left.3000^{\circ} \mathrm{F}\right)$, the curves are close together. As part of this effort, idle and blowout tests were not conducted. From the nature of the thick ceramic liners which held heat well, as the combustor was throttled down, it cooled slowly and it was difficult to determine the exact point of flame loss. Sandia ${ }^{13}$ performed blowout tests for the NASA injector at ambient temperature and pressure and found that its characteristics were excellent (with blowout at equivalence ratios of 0.1 ). They did mixing studies, measurement $\mathrm{OH}$, and stability the $\mathrm{CH}_{4}$, but did not measure the emissions of nitrogen oxides. 


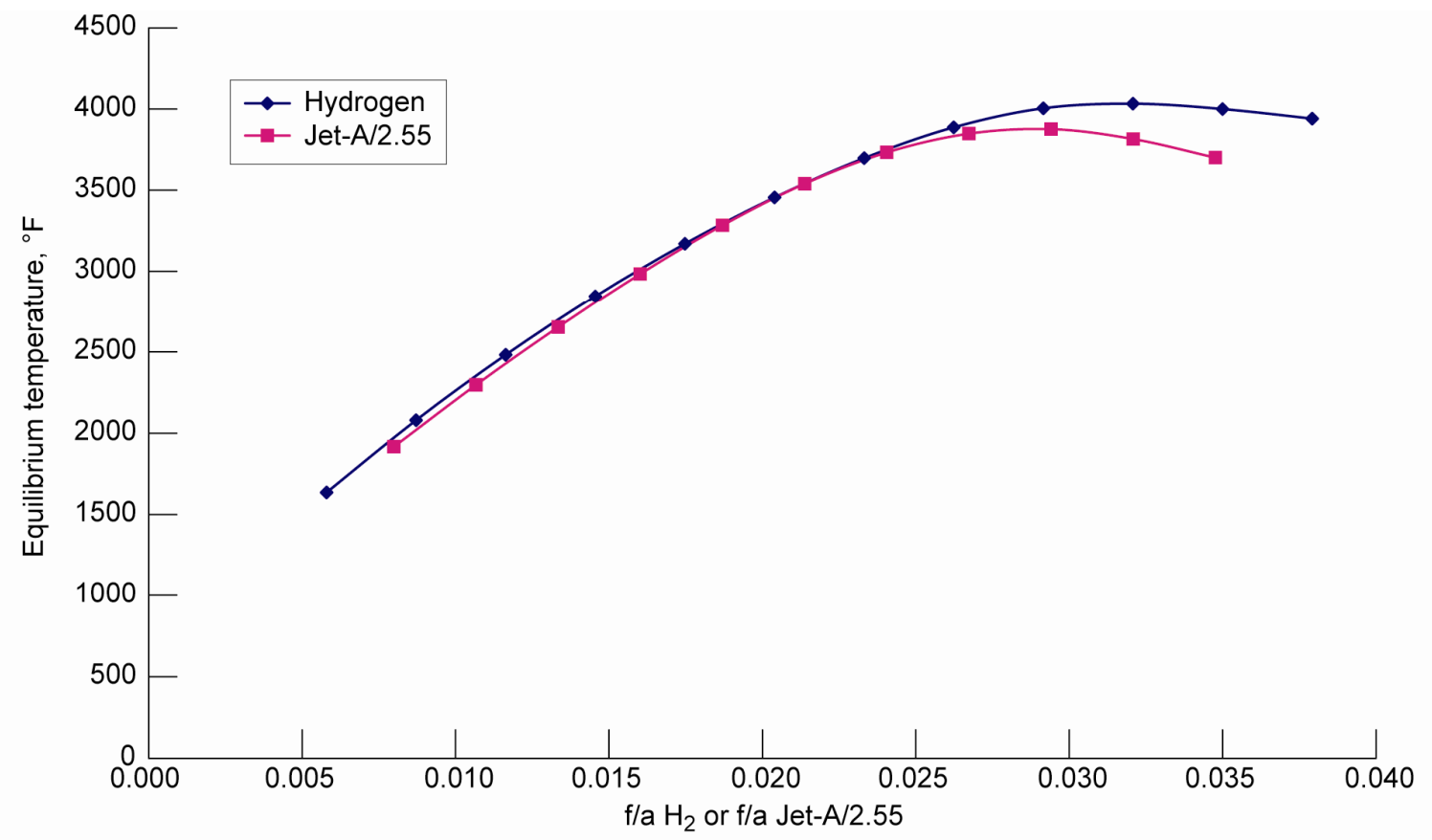

Figure 6. Equilibrium temperature ${ }^{\circ} \mathrm{F}$ for hydrogen or Jet-A. $\mathrm{P}=1 \mathrm{~atm}, \mathrm{~T}_{3}=70^{\circ} \mathrm{F}$.

\section{A. LDI Jet-A Correlation}

Significant work has been performed for LDI injectors for Jet-A, by Tacina. ${ }^{17}$ The exact correlation varies with the configuration, but a representative equation is given by Eq. (6). Eq. (6) was used as a measure for the emissions.

$$
E I_{\text {nox }}=A^{\prime *}\left(P_{3}\right)^{0.594} * \exp \left(\frac{T_{3}}{350}\right) *(f / a)^{1.6876} *\left(100 * \frac{\Delta P}{P}\right)^{-0.56}
$$

Where $A^{\prime}=14$-advanced LDI technology, used in this report

$=30$-current aircraft gas turbine combustors, AIAA-90-2004 ${ }^{18}$

$=53$-for 1980 technology aircraft combustors, AIAA-90-2004 ${ }^{18}$

$$
\mathrm{EI}=\left(\frac{\mathrm{gm} \mathrm{NO}}{\mathrm{x} \text { in the exhaust }}\right) \text { is called the emission index. }
$$

As stated previously, the preference is to present $\mathrm{NO}_{\mathrm{x}}$ data as parts/million (ppm). The molar parts/million (ppm) of $\mathrm{NO}_{\mathrm{x}}$ for Jet-A is given by:

$$
\text { ppm }_{\text {nox }}=\operatorname{EINO}_{x} * \frac{f / a}{(1+f / a)} * 630
$$

Equations (6) and (7) were combined and used for reference on the plots for comparison with the hydrogen data. The $f / a$ used in Eqs. (6) and (7) was $f / a_{\text {hydrogen }} * 2.55\left(\phi_{\mathrm{H} 2} * 0.0292 * 2.55\right)$.

\section{B. NASA N1 Injector with 2.5 in. liner}

Figure 7 shows the effect of equivalence ratio on $\mathrm{NO}_{\mathrm{x}} \mathrm{ppm}$ at a fixed inlet temperature $\left(T_{3}\right)$ and inlet pressure $\left(\mathrm{P}_{3}\right)$.

The data at three different probe positions are shown as well as the wall (within $0.0125 \mathrm{in}$. of the wall) and centerline locations. The $\mathrm{NO}_{\mathrm{x}}$ is plotted versus $T_{4}{ }^{\circ} \mathrm{F}$ on the upper axis and as the equivalence ratio at the nominal $T_{3}{ }^{\circ} \mathrm{F}$ on the lower axis

$$
\phi=7.1 E-5^{*}(T 4-T 3)^{1.157} ; \quad T 4<3600^{\circ} \mathrm{F}
$$

or the complement

$$
T 4-T 3=3704 * \phi^{0.86} ; T_{4}<3600^{\circ} \mathrm{F}
$$




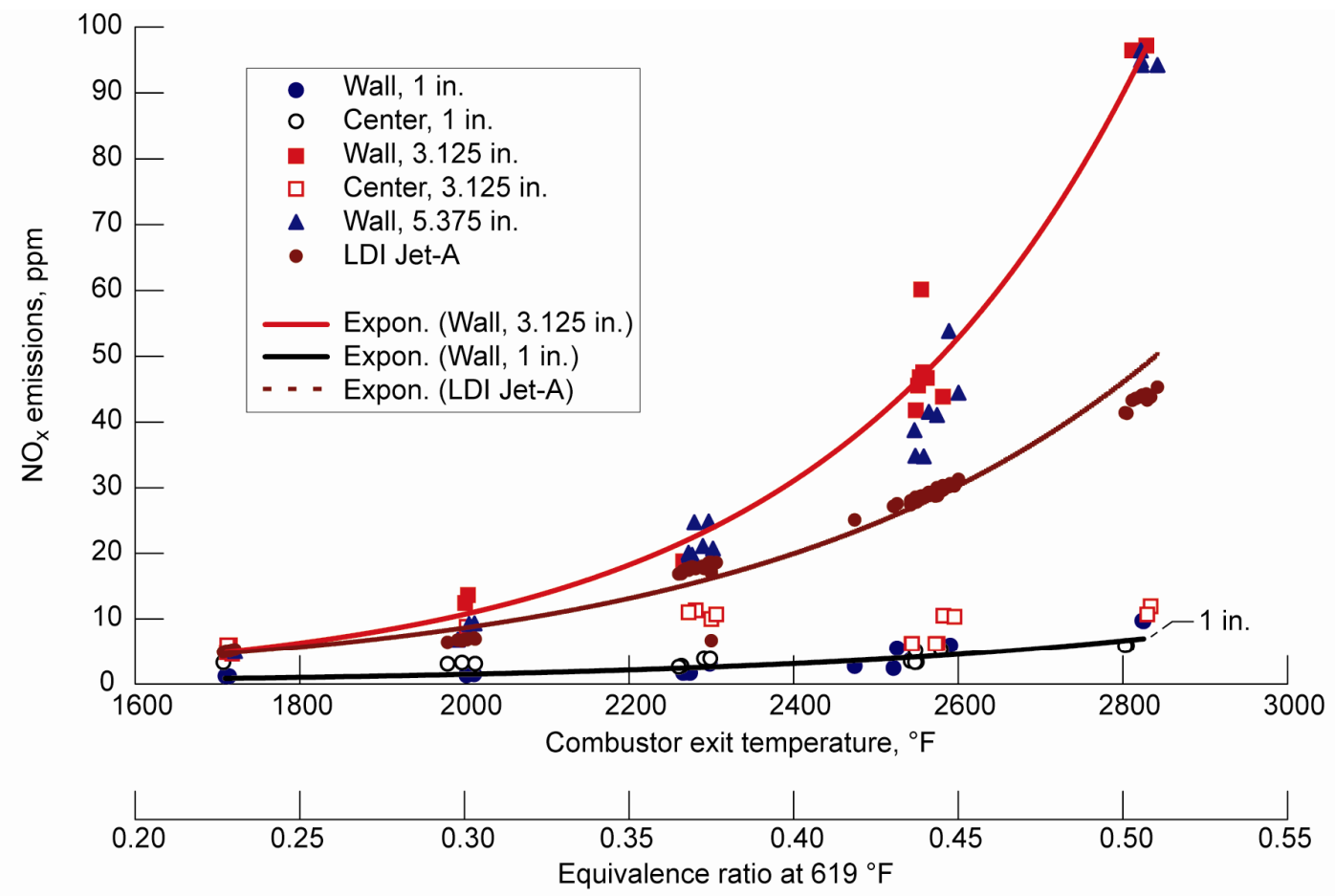

Figure 7. NASA N1 injector, 2.5 in. liner. $P=100$ psia, $T_{3}=619^{\circ} \mathrm{F}, V_{\text {ref }}=100 \mathrm{ft} / \mathrm{s}$.

The data is plotted accurately for the temperature axis. Since the equivalence ratio is not quite linear in $T_{4}$, both ends of the equivalence ratio scales are fixed and there maybe a $10 \%$ variation in the true equivalence ratio at mid scale. Also shown is the LDI-Jet-A correlation (Eq. (6) above, $A^{\prime}=14$ ). This was presented for each configuration where data exists. The scatter in the data appears high, however this was the first configuration tested. There was some variation in the inlet conditions as seen in the scatter in the LDI-Jet-A points which are plotted at the same conditions as the experimental data. Also the data for configuration NASA N1 was taken over a 4 month period of time. It took time to perfect the experimental technique. The failure of the thick ceramic liner was a problem. When the liner failed it had to be completely replaced and this took time. If the conditions were not set exactly the same, there was some variation in the data. The LDI-Jet-A correlation is not a function of residence time. Note that Eq. (6) does not have a time factor, because Jet-A combustors were not as sensitive to combustor residence time. The LDI Jet-A data was taken at distances of 4 and 8 in. from the face of the injector. Since the hydrogen reaction rates are over seven times faster than Jet-A, and there is no $\mathrm{CO}$ formation requiring burnout, short distances can be used. The $\mathrm{NO}_{\mathrm{x}}$ did not increase significantly from 3.125 and $5.375 \mathrm{in}$., similar to the LDI Jet-A data. The radical concentrations maybe reduced from the assumed higher levels near the injector. One difficulty with the NASA injector was the maldistribution of hydrogen across the face. The center holes were about $15 \%$ leaner than the mean as will be discussed later. This is evident in the large difference in the 3.125 in. data with the wall data being above the centerline data for a given measured $\phi$.

All of the data reported were with hydrogen efficiencies of $100 \%$ as determined by the hydrogen gas analysis from two sensors, a high range 0 to $4 \%$ hydrogen and the other from 0 to $1000 \mathrm{ppm}$ the readings were stable for over 10 seconds.. The low levels of $\mathrm{NO}_{\mathrm{x}}$ at low equivalence ratios are squeezed to values near the equivalence ratio axis and are difficult to differentiate. Since the exponential trend line follows the data well, a logarithmic scale of these values expands these values as shown in Fig. 8.

The advantage of hydrogen combustion for short times $\left(1.0 \mathrm{in}\right.$.) is clearly seen. The $\mathrm{NO}_{\mathrm{x}}$ emissions were 5 times lower than the Jet-A data out all conditions..

\section{Higher Temperature Data}

The data at inlet temperatures of 800 and $980{ }^{\circ} \mathrm{F}$ are shown in Figs. 9 and 10 and follow the same trend as the lower temperature data. The value of reference velocity has been increased as the inlet temperature was increased. These figures present the level and trends of the nitrogen oxide $\mathrm{NO}_{\mathrm{x}}$ emissions. The higher temperature data is similar to that shown in Fig. (7). 


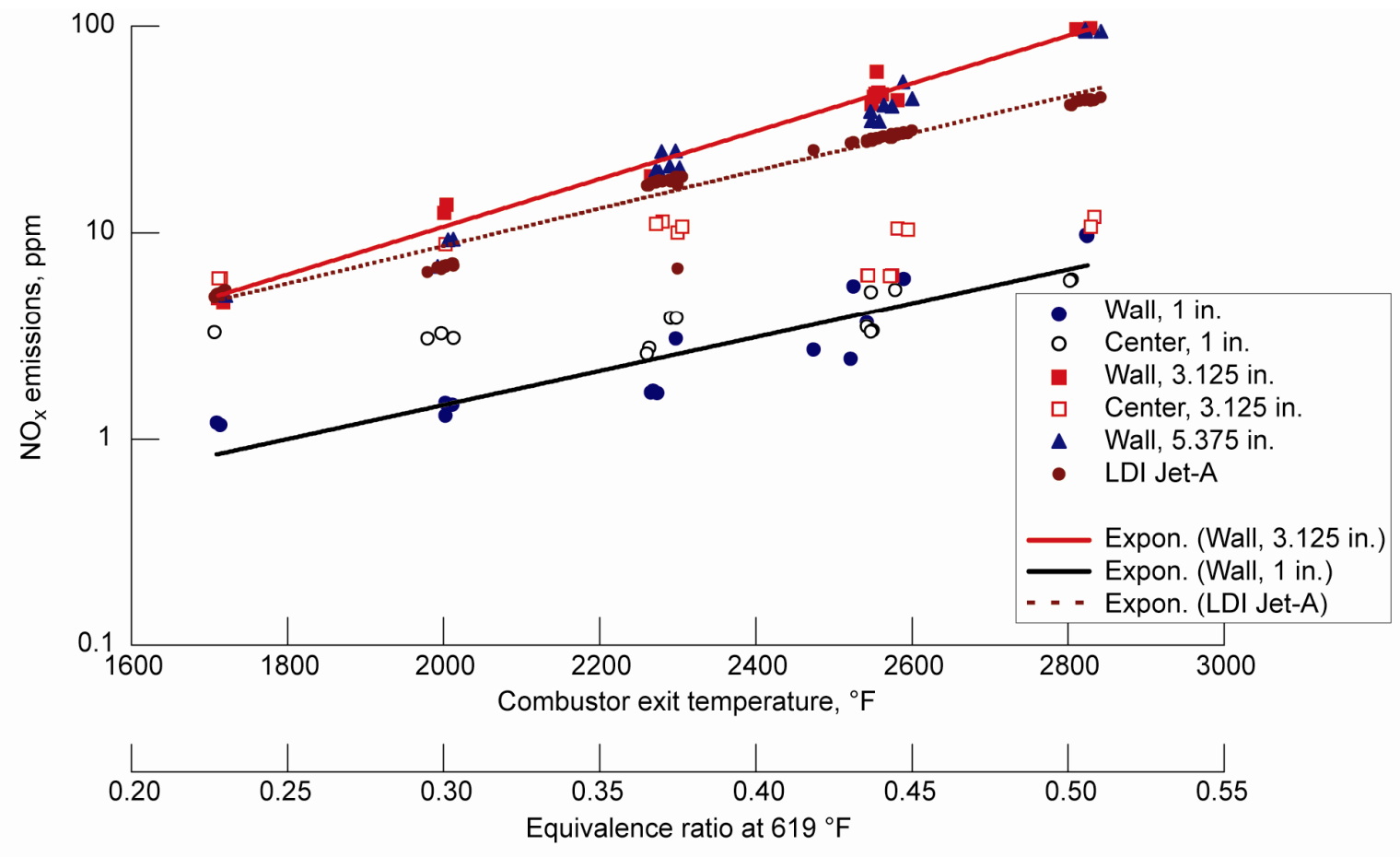

Figure 8. NASA N1 injector, 2.5 in. liner. $P=100 \mathrm{psia}, T_{3}=619^{\circ} \mathrm{F}, \mathrm{V}_{\mathrm{ref}}=100 \mathrm{ft} / \mathrm{s}$.

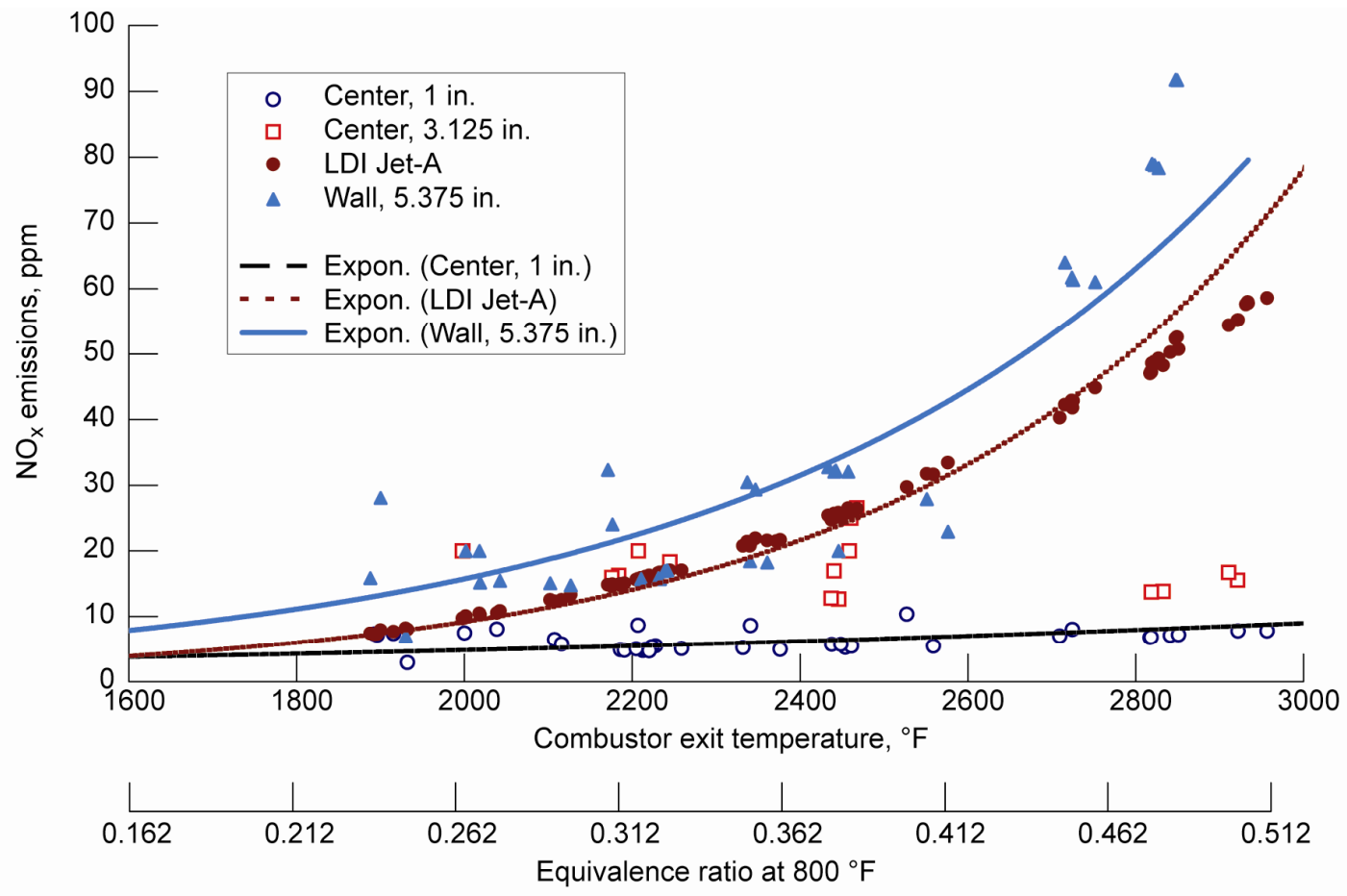

Figure 9. NASA N1 injector, 2.5 in. liner. $P=100 \mathrm{psia}, \mathrm{T}_{3}=800^{\circ} \mathrm{F}, \mathrm{V}_{\mathrm{ref}}=130 \mathrm{ft} / \mathrm{s}$. 


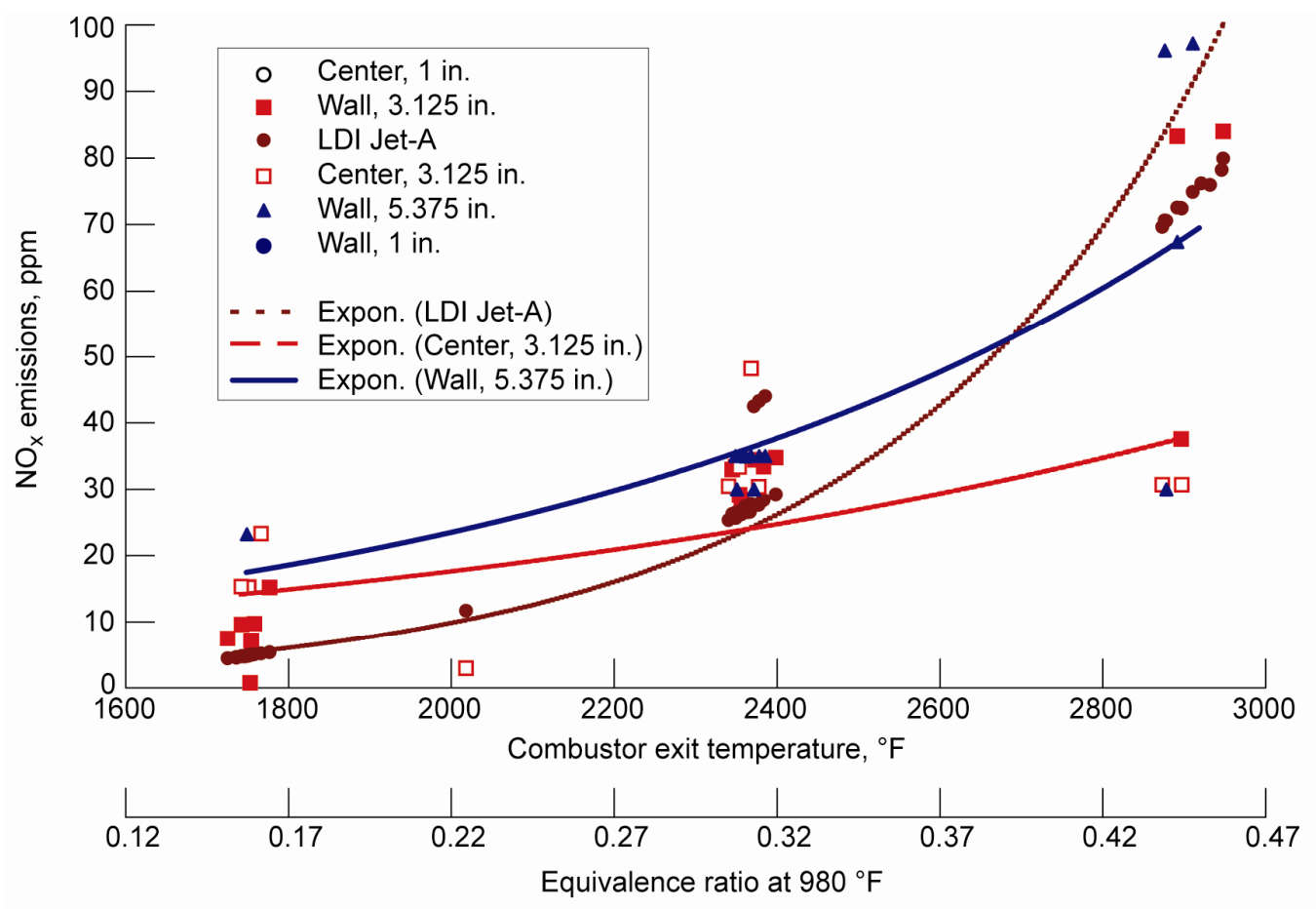

Figure 10. NASA N1 injector, 2.5 in. liner. $P=100 \mathrm{psia}, \mathrm{T}_{3}=980^{\circ} \mathrm{F}, \mathrm{V}_{\text {ref }}=150 \mathrm{ft} / \mathrm{s}$.

\section{Equivalence Ratio Based on Oxygen Concentration}

For lean mixtures, the $\mathrm{H}_{2}$ /Air mole balance assuming complete combustion is:

$$
\phi \mathrm{H}_{2}+1 / 2 \mathrm{O}_{2}+1 / 2(79 / 21) \mathrm{N}_{2}=\phi \mathrm{H}_{2} \mathrm{O}+(1-\phi) 1 / 2 \mathrm{O}_{2}+1 / 2(79 / 21) \mathrm{N}_{2}
$$

Therefore the dry $\mathrm{O}_{2}$ mole fraction (oxygen is measured on a dry basis) in the gas analysis stream is:

$$
\mathrm{O}_{2}=\frac{21 *(1-\phi)}{21 *(1-\phi)+79}
$$

Rearranging, the equivalence ratio based on the oxygen mole fraction measurement is:

$$
\phi_{\mathrm{O}_{2}}=\frac{21-100 * \mathrm{O}_{2}}{21 *\left(1-\mathrm{O}_{2}\right)}
$$

Equation (10) was used to compute the local stoichiometry from the oxygen measurement. The probe equivalence ratio versus the metered overall equivalence ratio is shown in Fig. 11.

The fuel concentration was lower in the center by $15 \%$ than at the wall $(10 \%$ high) because of the nonuniform manifolding to the center holes. The metering holes which were shown in Fig. 4 should have produced uniform flow, but with hydrogen cooling of the injector face. The heating is not uniform which creates a nonuniform flow out of the injector because of changes in density.

The $\mathrm{NO}_{\mathrm{x}}$ levels wet versus the equivalence ratio based on oxygen is shown in Fig. 12. There is considerable collapse of the data showing the large reduction of the $\mathrm{NO}_{\mathrm{x}}$ over the LDI Jet-A correlation at one inch and comparable values at 3.125 in. The lean points are shifted to the left and the rich wall points are shifted to the right. The impact is clearly seen for the center 3.125 data (the open squares) by comparing Fig. 7 with Fig. 12. The squares at $2800{ }^{\circ} \mathrm{F}$ were shifted to $2200^{\circ} \mathrm{F}$. The LDI Jet-A data is also recomputed based on the oxygen equivalence ratio. All new trend lines were drawn through the data using the chart exponential trend function. Some scatter still exists. This might be caused by the slow response of the oxygen detector which required at least $1 \frac{1 / 2}{2}$ minutes to respond and two minutes to equilibrate. Earlier data may not have been fully equilibrated before the data was recorded.

The configurations $\mathrm{C} 1$ to $\mathrm{C} 4$ were very uniform by comparison of the wall to the centerline points. Hydrogen was metered individually to each hole rather that through stepped manifolds as in the NASA N1 injector (Fig. 5). 


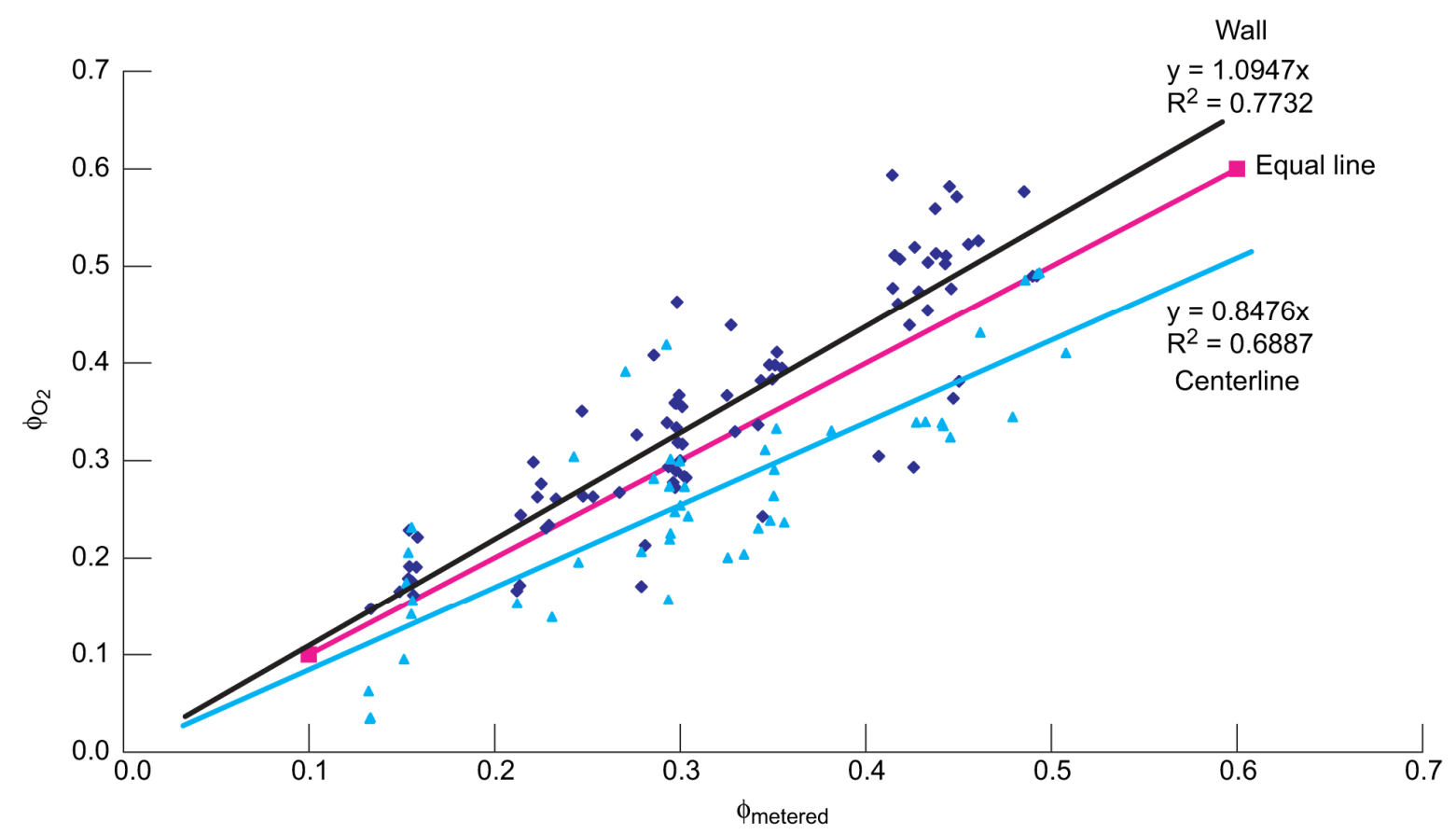

Figure 11. NASA N1 injector $\phi_{\mathrm{O}_{2}}$ vs $\phi_{\text {metered }}$.

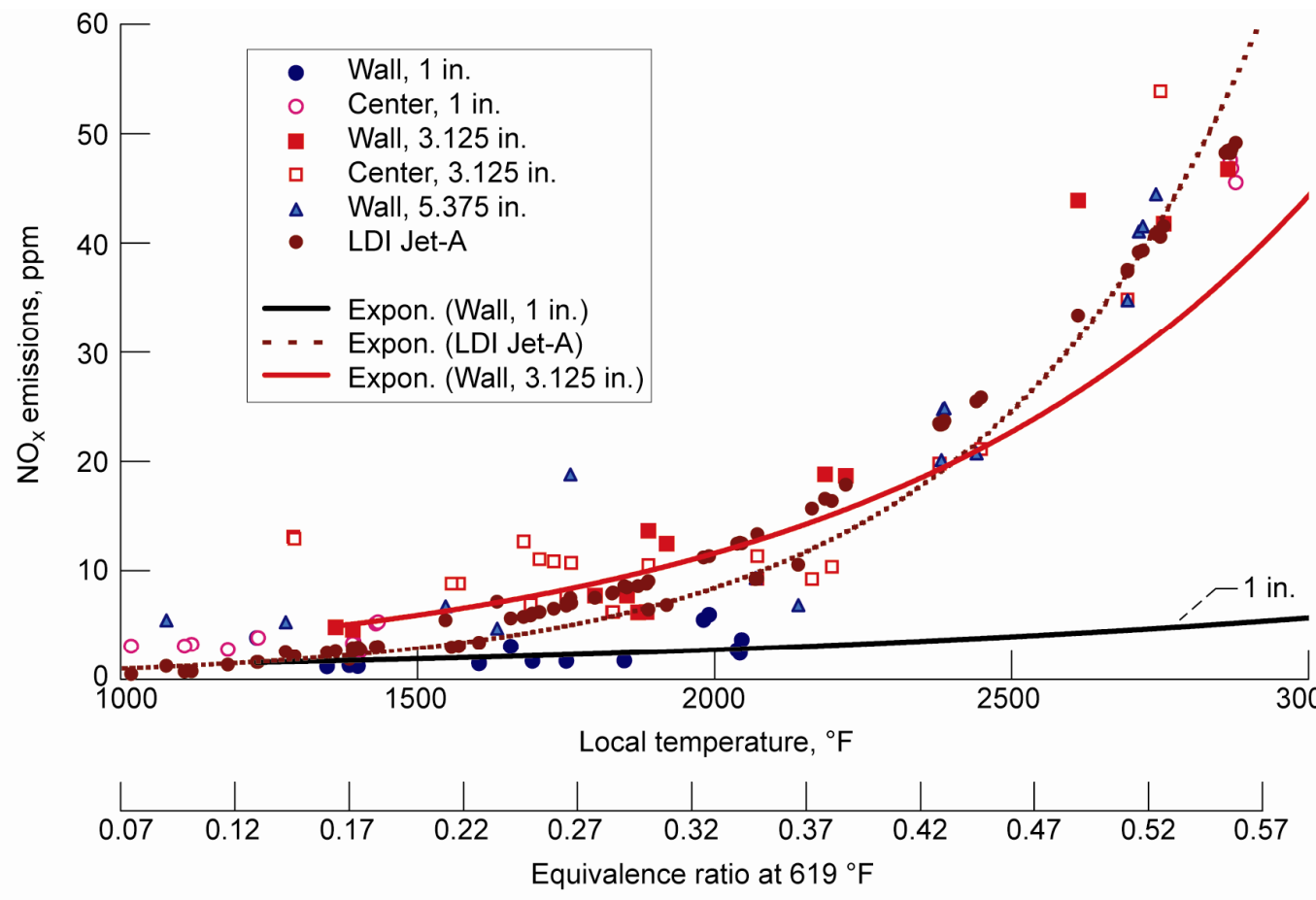

Figure 12. NASA N1 injector, 2.5 in. liner. $P=100$ psia, $T_{3}=619^{\circ} \mathrm{F}, V_{\text {ref }}=100 \mathrm{ft} / \mathrm{s}$. 


\section{E. Effect of Pressure}

The effect of pressure is shown in Fig. 13 at a $T_{3}$ of $980{ }^{\circ} \mathrm{F}$ and a reference velocity of $115 \mathrm{ft} / \mathrm{s}$. The change in $\mathrm{NO}_{\mathrm{x}} \mathrm{ppm}$ with equivalence ratio phi is very flat compared to the LDI Jet-A correlation. As the pressure is increased, the fuel flow must be increased resulting in more penetration and better mixing for the NASA N1 injector. Likewise at low equivalence ratio and high pressure, the $\mathrm{NO}_{\mathrm{x}}$ levels are greater than the LDI Jet-A data.

A common practice is to report the $\mathrm{NO}_{\mathrm{x}}$ data corrected to $15 \%$ oxygen. Nitrogen oxide emissions from ground power and ground transportation vehicles are typically corrected to $15 \%$ dry oxygen, so comparison with our data show calculations for the $\mathrm{NO}_{\mathrm{x}}$ corrected data in appendix A. However, this practice is not commonly done for aircraft gas turbine combustors and because this data is for use by the aircraft gas turbine industry, corrected data is not presented here.

\section{F. Configuration C1}

Figures 14 and 15 show the results of configuration $\mathrm{C} 1$.

At an axial location of 1.0-in., the $\mathrm{NO}_{\mathrm{x}} \mathrm{ppm}$ is low, about half of the LDI- Jet-A values. However, the values at 3.125 in. were double the Jet-A values. At $830^{\circ} \mathrm{F}$, Fig. 15, we believe a small failure occurred.

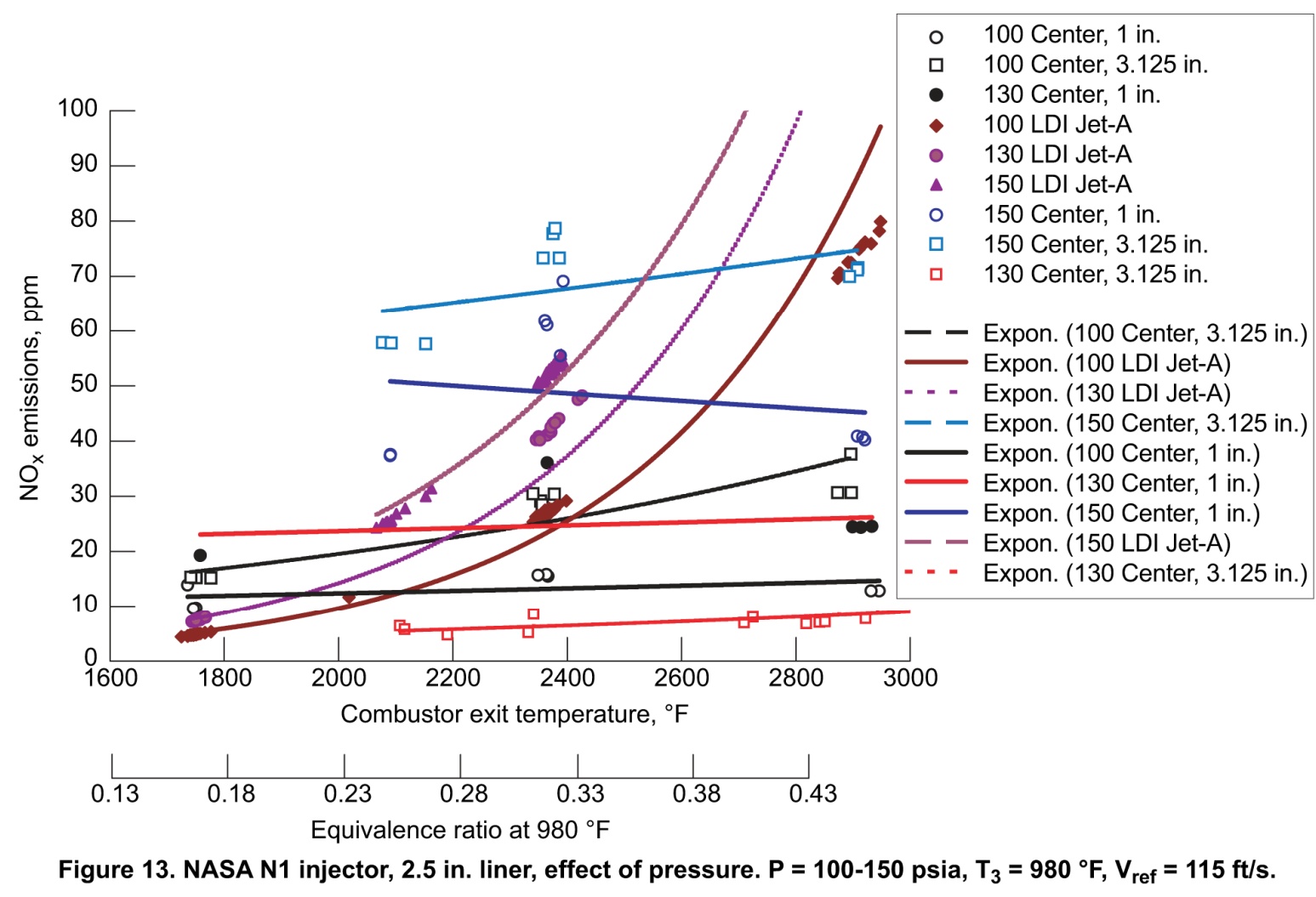




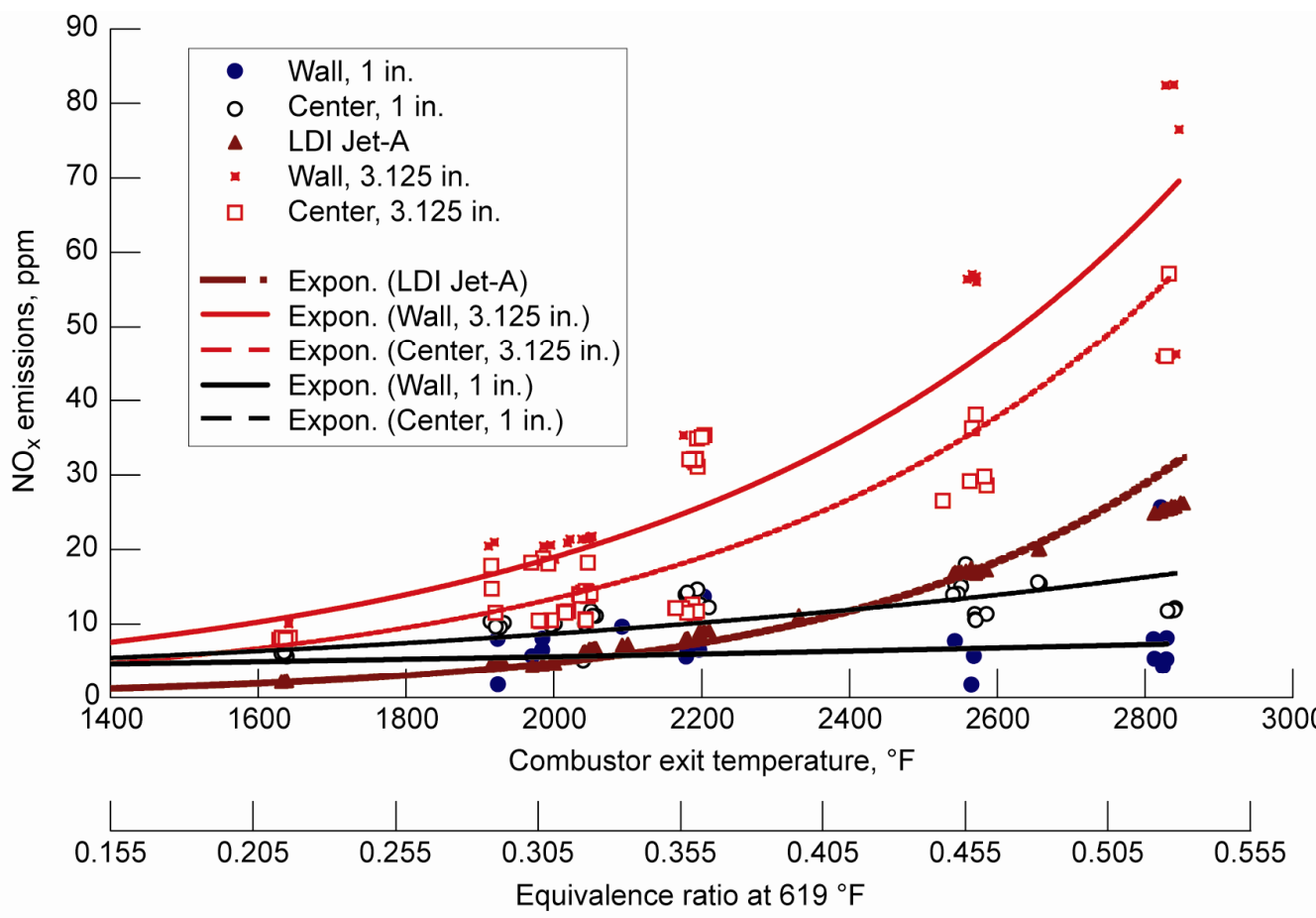

Figure 14. Configuration $\mathrm{C} 1$ injector, $2.5 \mathrm{in}$. liner, $\mathrm{NO}_{x}$ vs $\phi$ metered. $P=100 \mathrm{psia}, \mathrm{T}_{3}=630^{\circ} \mathrm{F}, \mathrm{V}_{\mathrm{ref}}=100 \mathrm{ft} / \mathrm{s}$.

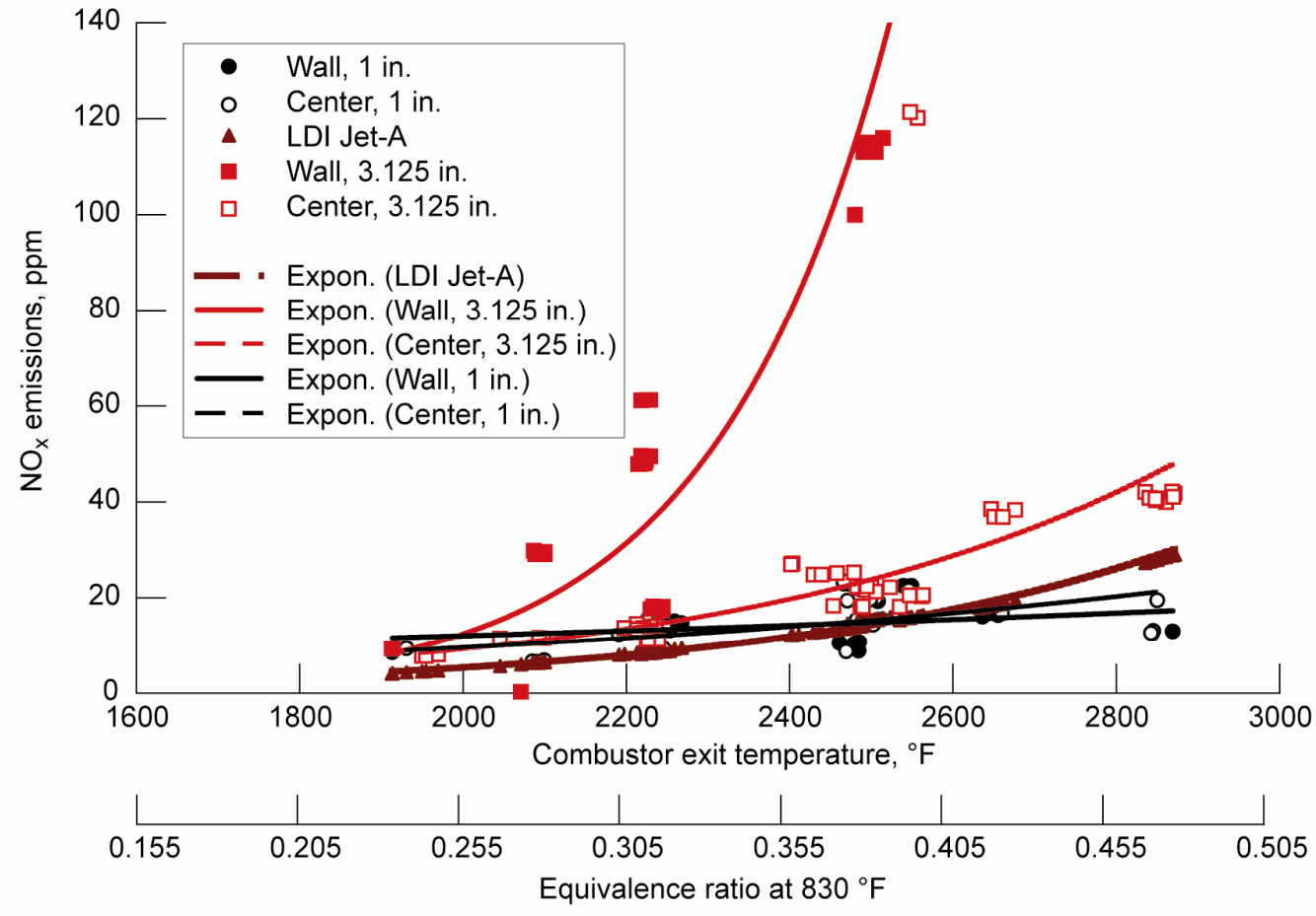

Figure 15. Configuration $\mathrm{C} 1$ injector, $2.5 \mathrm{in}$. liner, $\mathrm{NO}_{\mathrm{x}} \mathrm{vs} \phi_{\text {metered }} \mathrm{P}=100 \mathrm{psia}, \mathrm{T}_{3}=830^{\circ} \mathrm{F}, \mathrm{V}_{\mathrm{ref}}=100 \mathrm{ft} / \mathrm{s}$. 
It is important to mix quickly with hydrogen combustors. The maximum temperature at $\phi=1.0$ is $400{ }^{\circ} \mathrm{F}$ (Fig. 6), about the same as Jet-A. But because hydrogen reacts seven times faster than Jet-A this temperature can be achieved near the injector face while the hydrogen and air are still unmixed. This places extreme thermal stress on the injector face. All of the data from the injectors are correlated and compared later in the report. We performed the correlations on all of the data taken, without trying to remove data from a failed state.

\section{G. Configuration C2}

The configuration $\mathrm{C} 2$ injector contained 54 triangular LDI injectors with 3 hydrogen injection points per triangle in a honeycomb pattern. The $\mathrm{NO}_{\mathrm{x}}$ data is shown in Fig. 16.

It which resulted in fine detail and was difficult to manufacture. It used a unique pattern for quick mixing. The initial $\mathrm{NO}_{\mathrm{x}}$ levels were very low achieving less than half of the Jet-A levels, but it's cooling and durability was compromised and it failed resulting in nonuniform mixing and higher $\mathrm{NO}_{\mathrm{x}}$ readings for later data.

\section{H. Configuration C3}

Configuration $\mathrm{C} 3$ was conservative and included a single hole hydrogen injection with counter swirl for each of the seven LDI holes. Its performance is shown in Figs. 17 through 19.

The minimum $\mathrm{NO}_{\mathrm{x}}$ levels were twice that of the LDI Jet-A values which was poorer, however, the configuration was very durable.

\section{Configuration $\mathrm{C} 4$}

The data for configuration C4 is shown in Figs. 20 through 23. This design included 4 small hydrogen diameter injection holes directed at an angle upstream per LDI hole. The swirlers were removed to reduce the pressure drop. The $\mathrm{NO}_{\mathrm{x}}$ values were much lower that the LDI Jet-A levels, almost half the values over a wide range of equivalence ratios to an exit temperature of $2600{ }^{\circ} \mathrm{F}$. This configuration was the best tested over the complete range of conditions. It also proved to be very durable. Figure 23 shows that configuration $\mathrm{C} 4$ was well mixed radially.

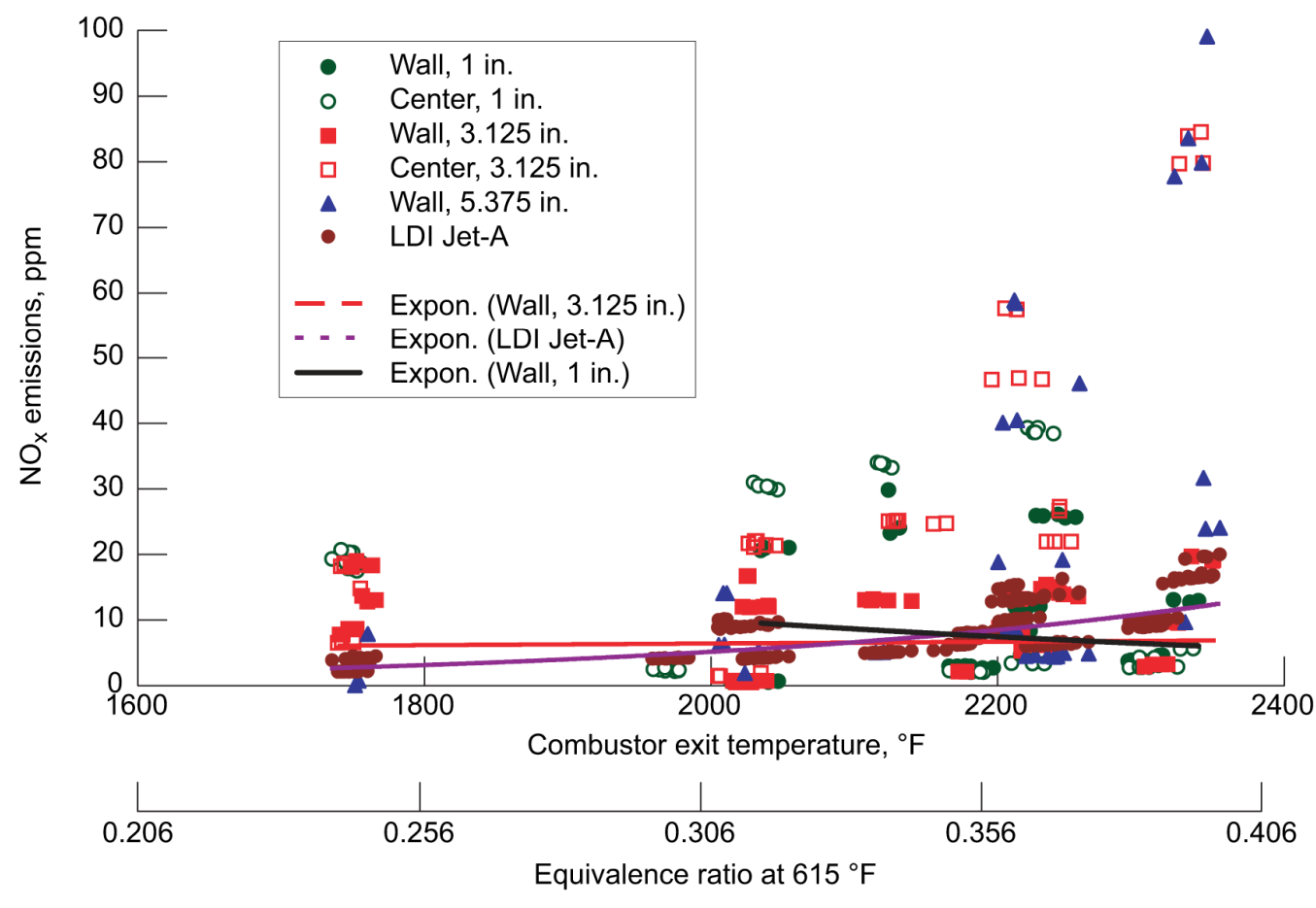

Figure 16. Configuration $C 2$ injector, 2.5 in. liner. $P=70$ psia, $T_{3}=615^{\circ} \mathrm{F}, V_{\text {ref }}=125 \mathrm{ft} / \mathrm{s}$. 

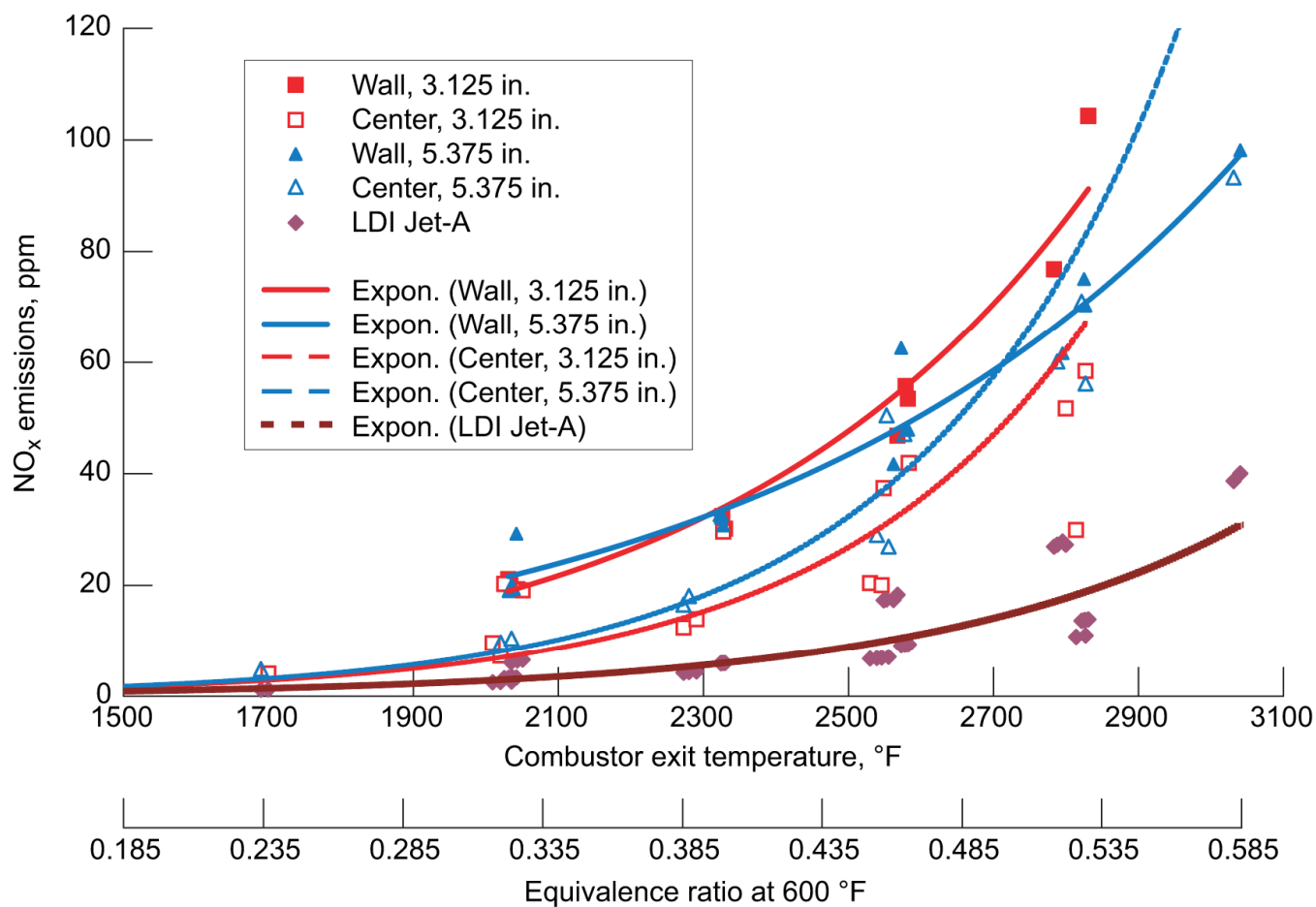

Figure 17. Configuration $C 3,3.5$ in. liner. $P=100$ psia, $T_{3}=600^{\circ} \mathrm{F}, V_{\text {ref }}=70 \mathrm{ft} / \mathrm{s}$.

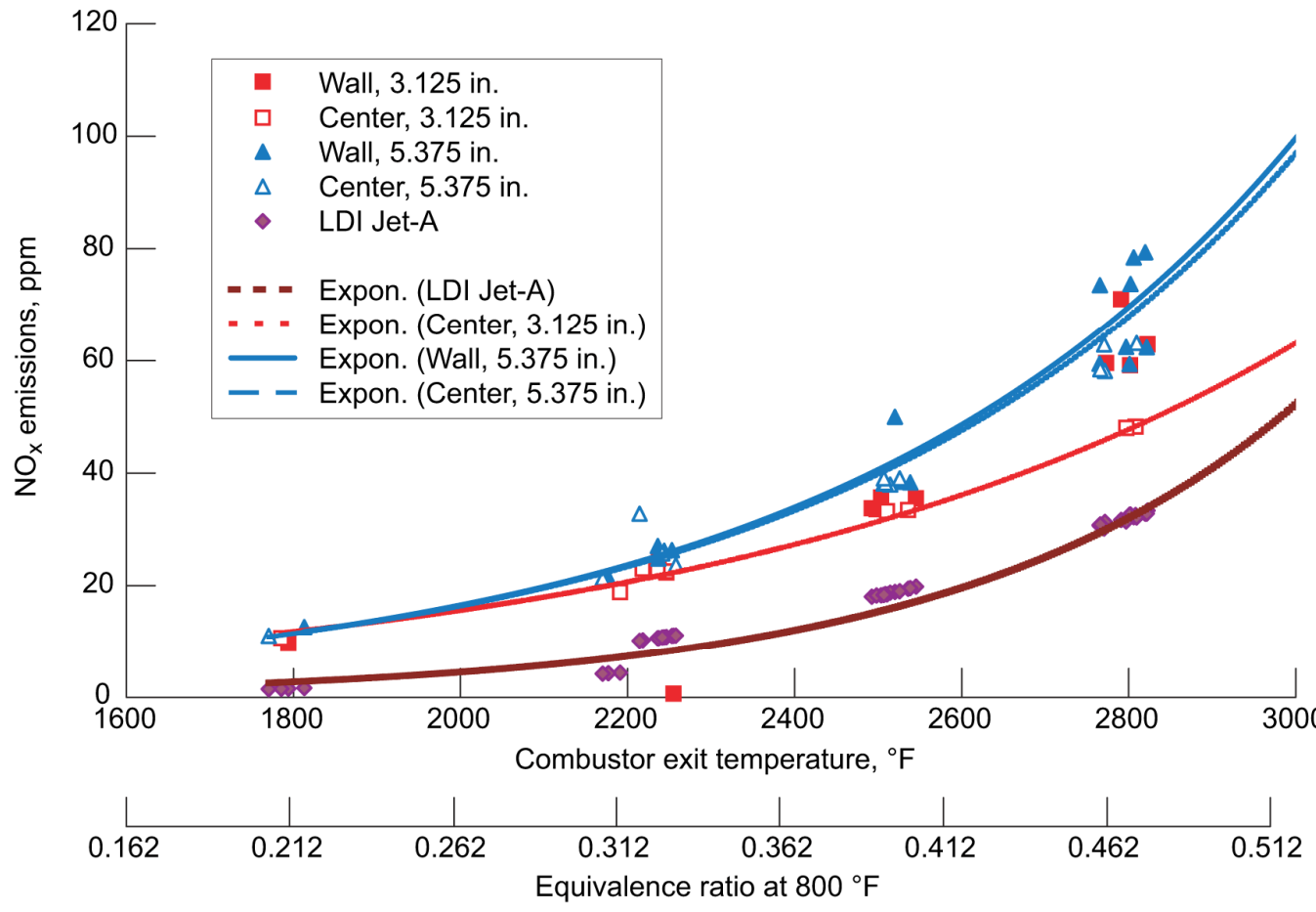

Figure 18. Configuration $\mathrm{C} 3,3.5$ in. liner. $P=100 \mathrm{psia}, \mathrm{T}_{3}=800^{\circ} \mathrm{F}, \mathrm{V}_{\text {ref }}=70 \mathrm{ft} / \mathrm{s}$.

American Institute of Aeronautics and Astronautics 


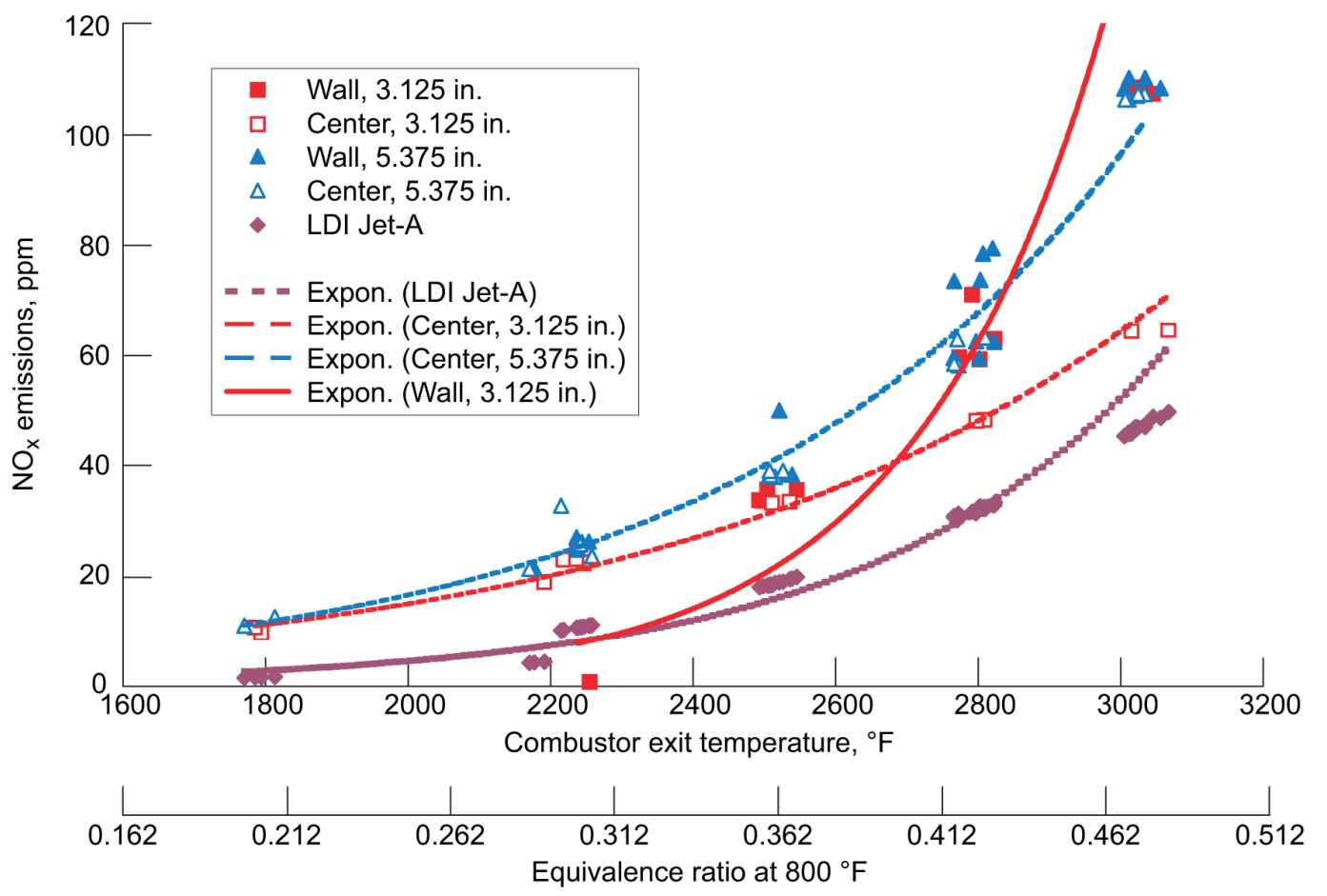

Figure 19. Configuration $C 3,3.5$ in. liner. $P=100$ psia, $T_{3}=800^{\circ} \mathrm{F}, V_{\text {ref }}=70 \mathrm{ft} / \mathrm{s}$.

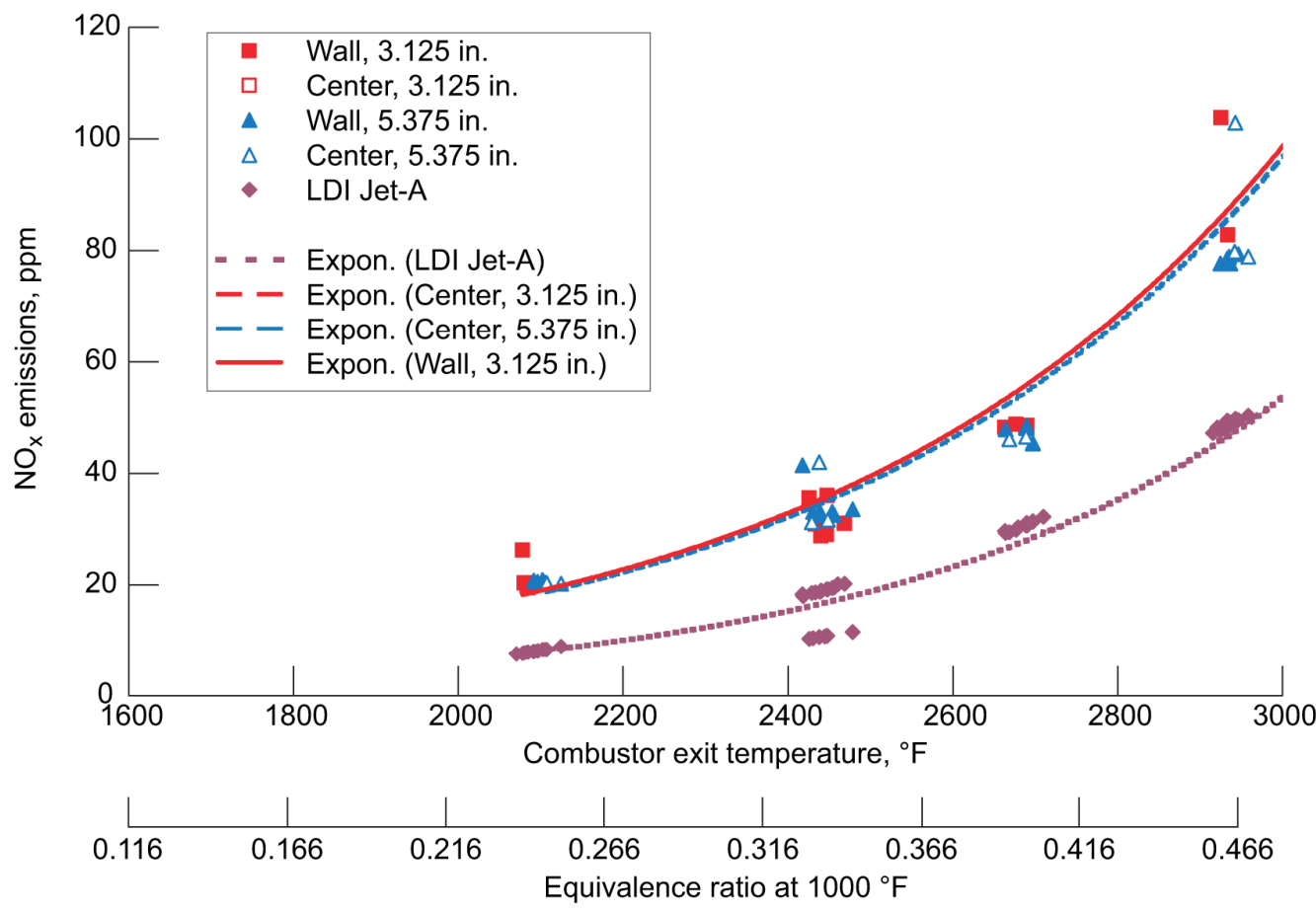

Figure 20. Configuration $C 3,3.5$ in. liner. $P=100$ psia, $T_{3}=1000^{\circ} \mathrm{F}, V_{\text {ref }}=70 \mathrm{ft} / \mathrm{s}$. 

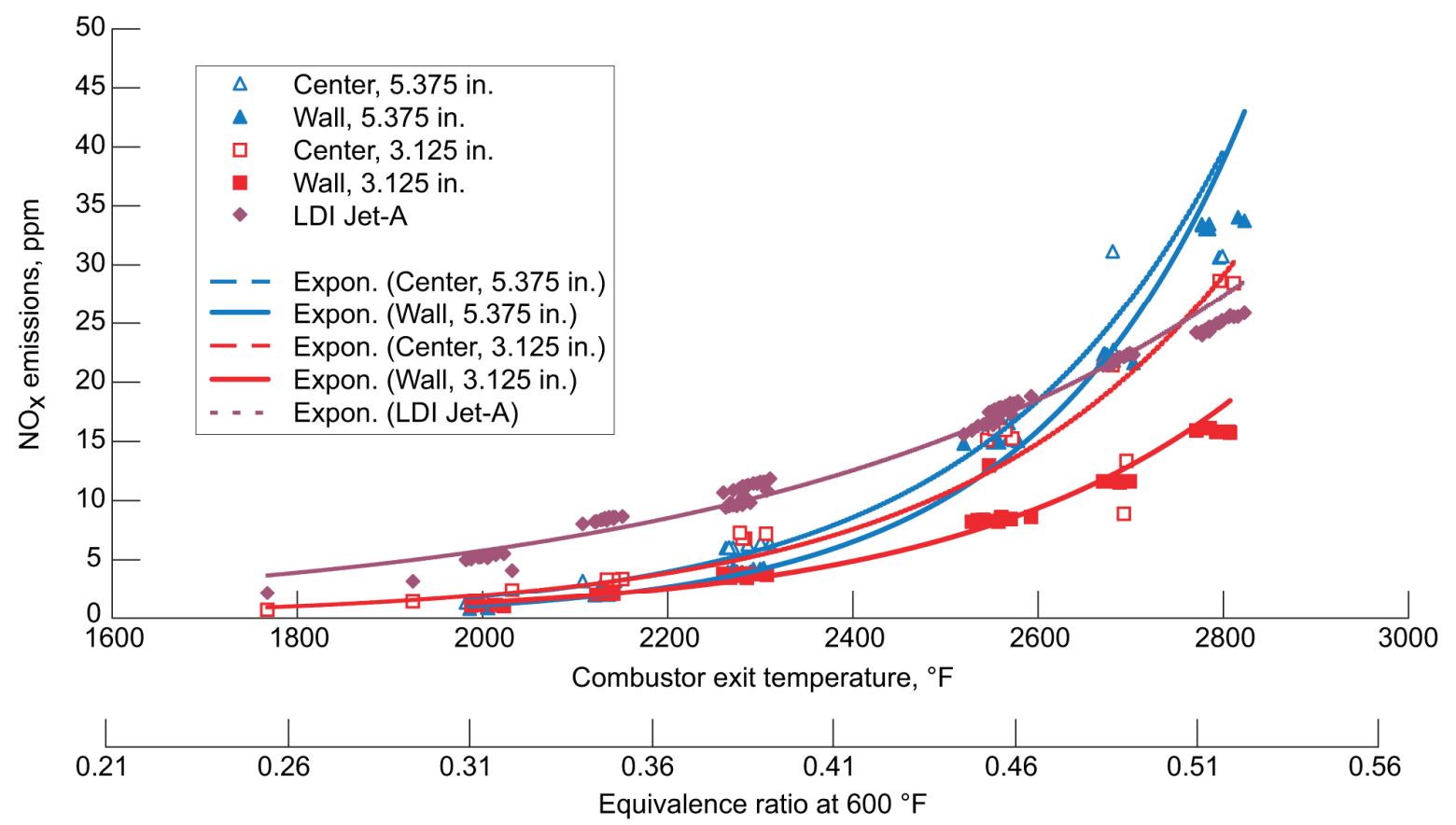

Figure 21. Configuration $C 4,3.5 \mathrm{in}$. liner. $P=100 \mathrm{psia}, \mathrm{T}_{3}=600^{\circ} \mathrm{F}, \mathrm{V}_{\text {ref }}=60 \mathrm{ft} / \mathrm{s}$.

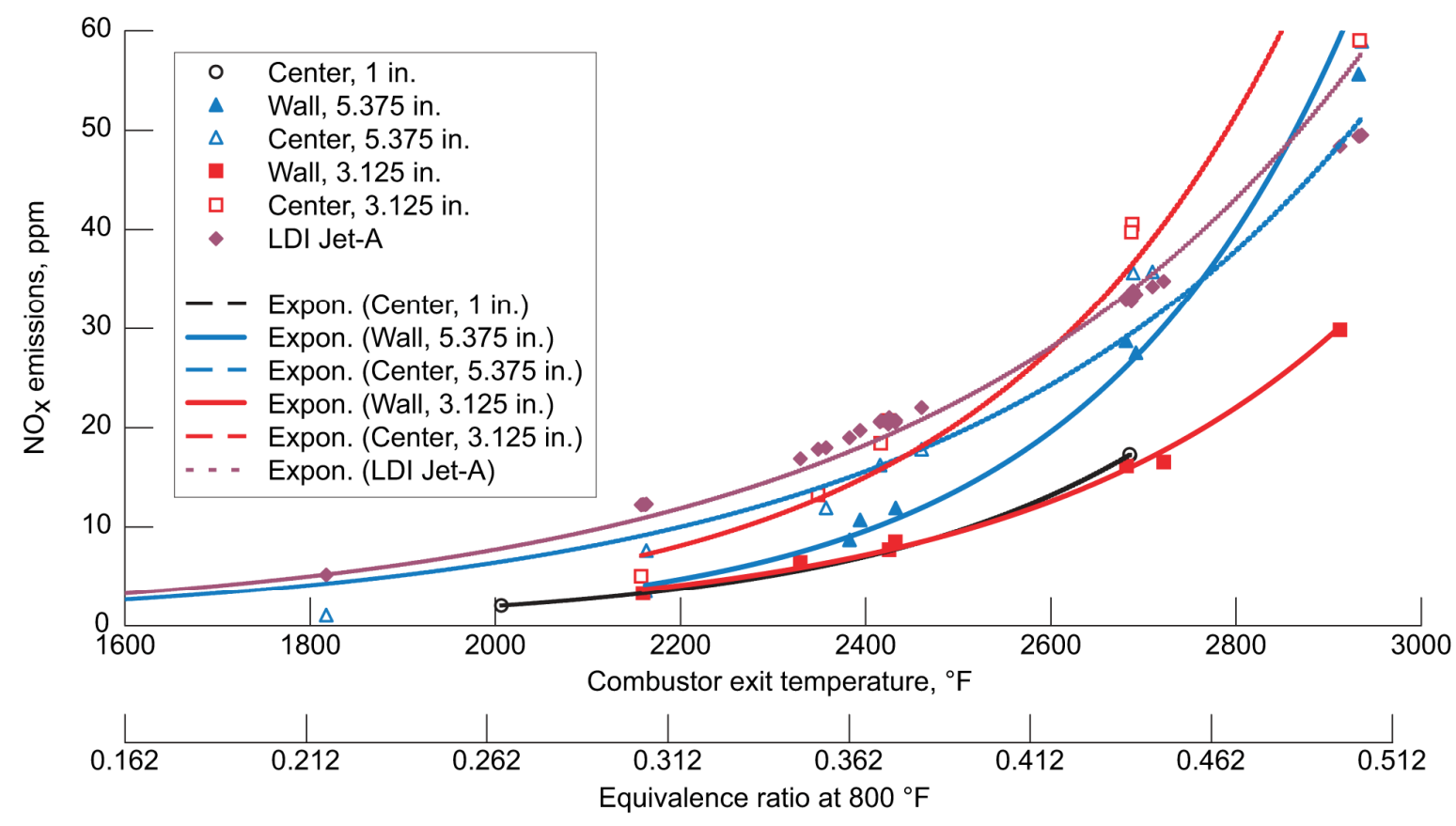

Figure 22. Configuration $\mathrm{C} 4,3.5 \mathrm{in}$. liner. $\mathrm{P}=100 \mathrm{psia}, \mathrm{T}_{3}=800^{\circ} \mathrm{F}, \mathrm{V}_{\text {ref }}=60 \mathrm{ft} / \mathrm{s}$. 


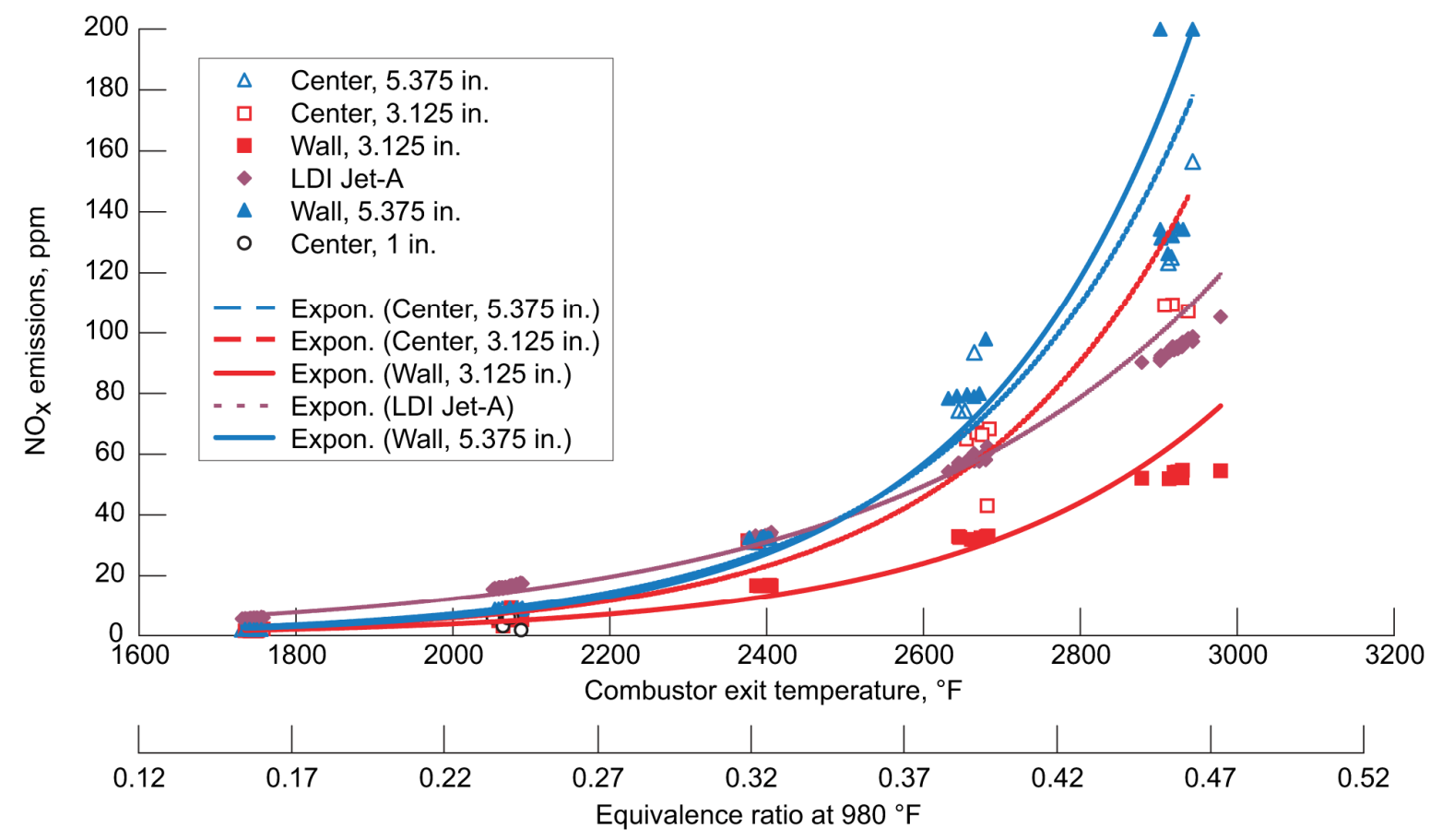

Figure 23. Configuration $C 4,3.5$ in. liner. $P=150$ psia, $T_{3}=980^{\circ} \mathrm{F}, V_{\text {ref }}=60 \mathrm{ft} / \mathrm{s}$.

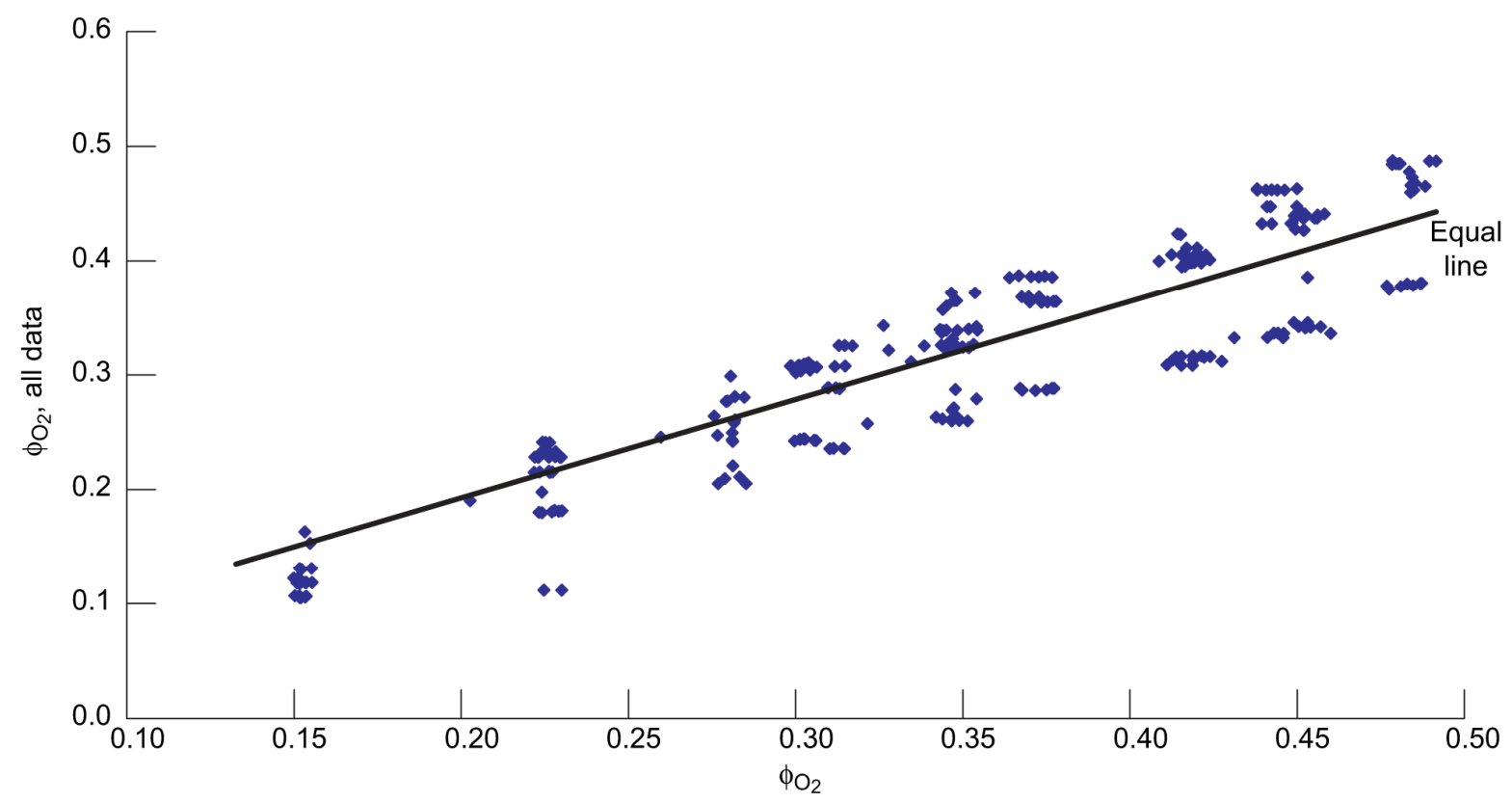

Figure 24. Configuration C4 equivalence ratio metered vs equivalence ratio based on oxygen, all data.

\section{J. NASA N1 Injector with 3.5 inch liner}

The data for the NASA N1 injector with a 3.5-in. liner is shown in Figs. 24 through 29. The data is significantly different from that of the 2.5-in. liner.

When using the 3.5-in. liner, the corner recirculation zones were much larger than for the 2.5-in. liner, providing longer residence times for the production of $\mathrm{NO}_{\mathrm{x}}$. The injector itself was not changed so the effective blockage increases to $86 \%$, increasing the pressure loss to $10 \%$. This configuration was tested at the reduced reference 
velocity of $60 \mathrm{ft} / \mathrm{s}$ or a $\triangle P / P$ of $3.6 \%$. The wall $\mathrm{NO}_{\mathrm{x}}$ was higher than the centerline values for the NASA injector. Data for the NASA injector at 1.0-in. were not taken, because the probe traverse failed at this location. $\mathrm{The}^{\mathrm{NO}} \mathrm{x}$ is higher than the 2.5 -in. liner, because we were testing at only $60 \mathrm{ft} / \mathrm{s}$.

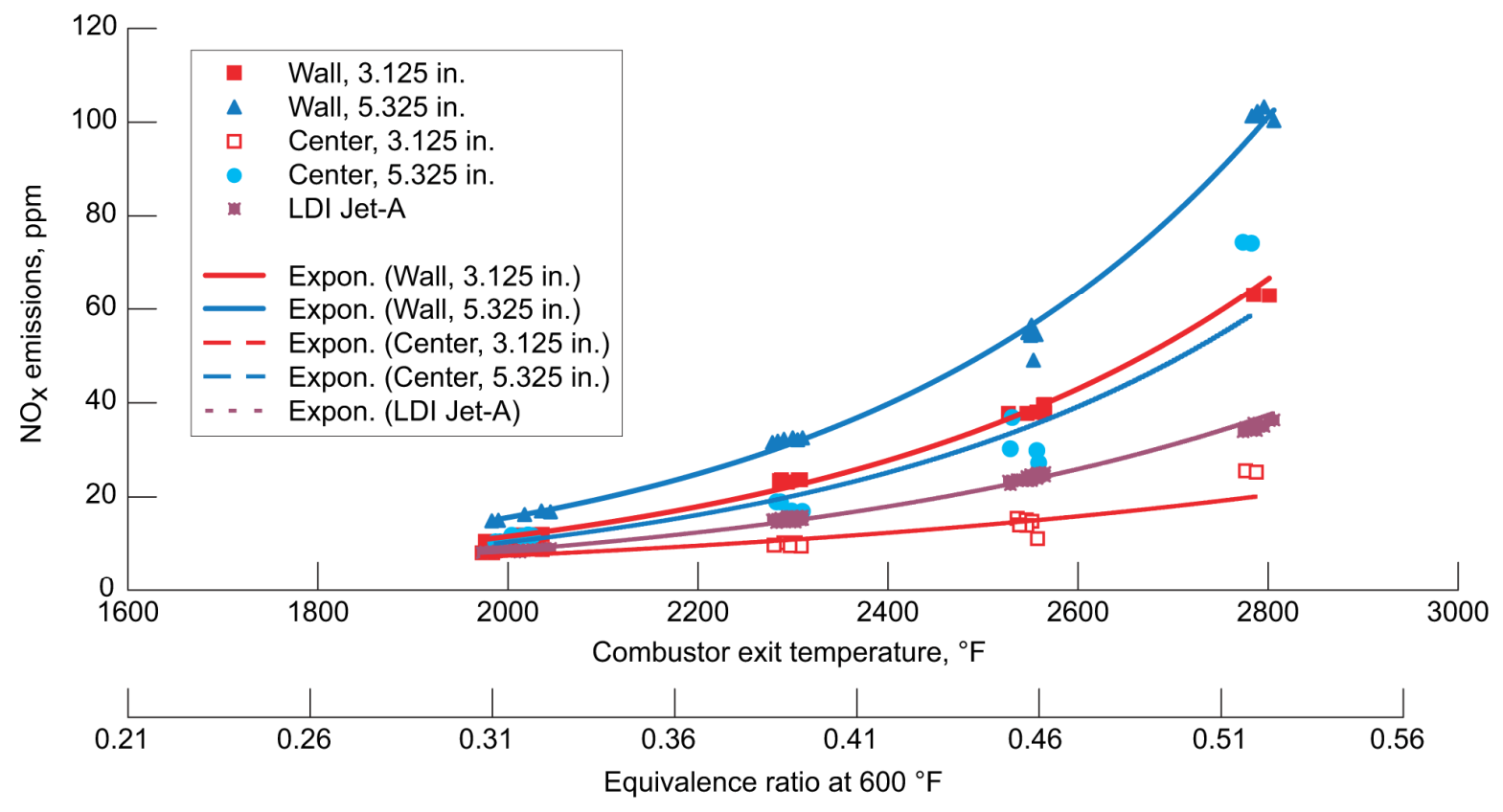

Figure 25. NASA N1 injector, 3.5 in. liner. $P=100 \mathrm{psia}, \mathrm{T}_{3}=600^{\circ} \mathrm{F}, \mathrm{V}_{\mathrm{ref}}=60 \mathrm{ft} / \mathrm{s}$.

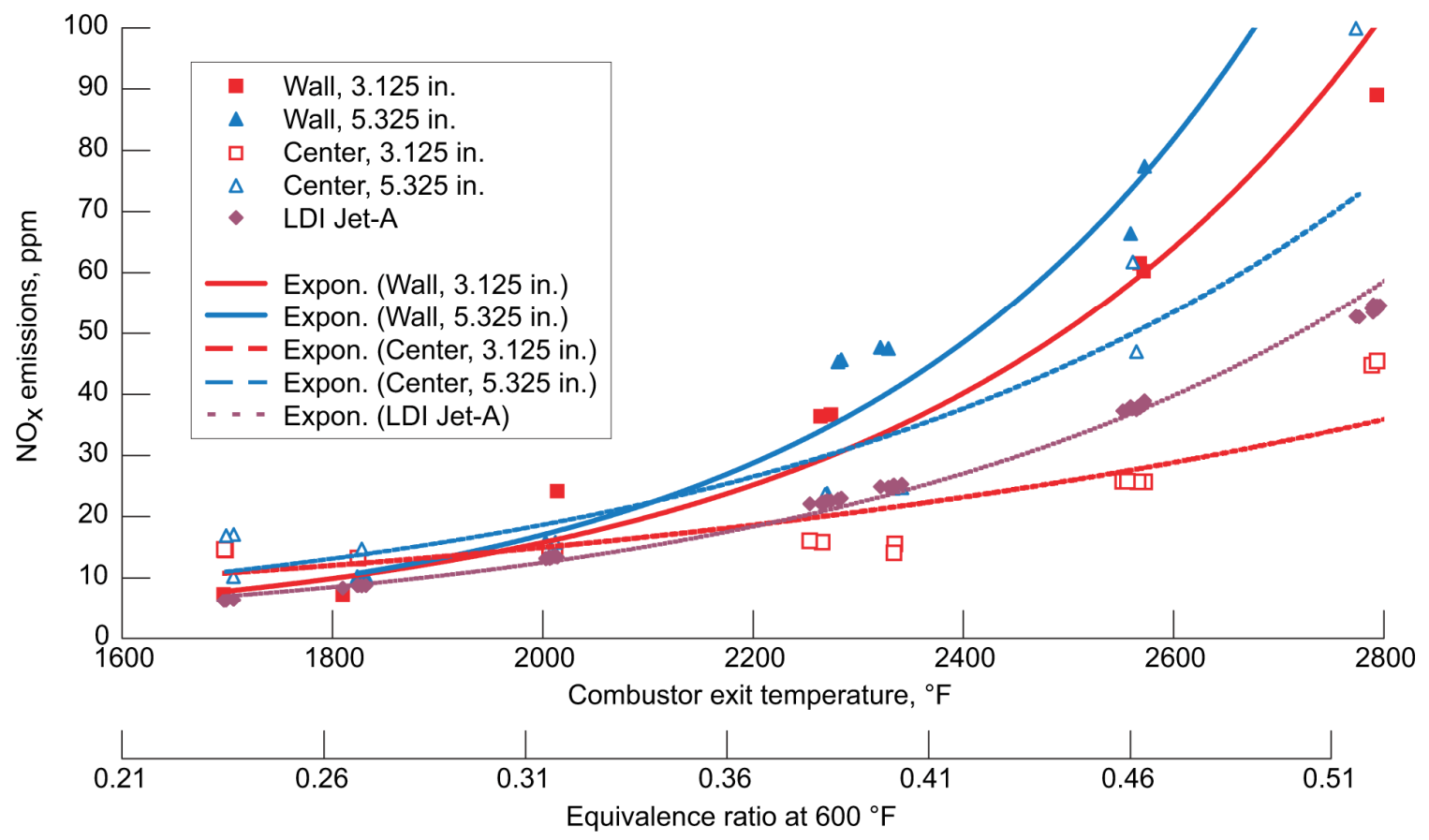

Figure 26. NASA N1, 3.5 in. liner. $P=200 \mathrm{psia}, \mathrm{T}_{3}=600^{\circ} \mathrm{F}, \mathrm{V}_{\text {ref }}=60 \mathrm{ft} / \mathrm{s}$. 


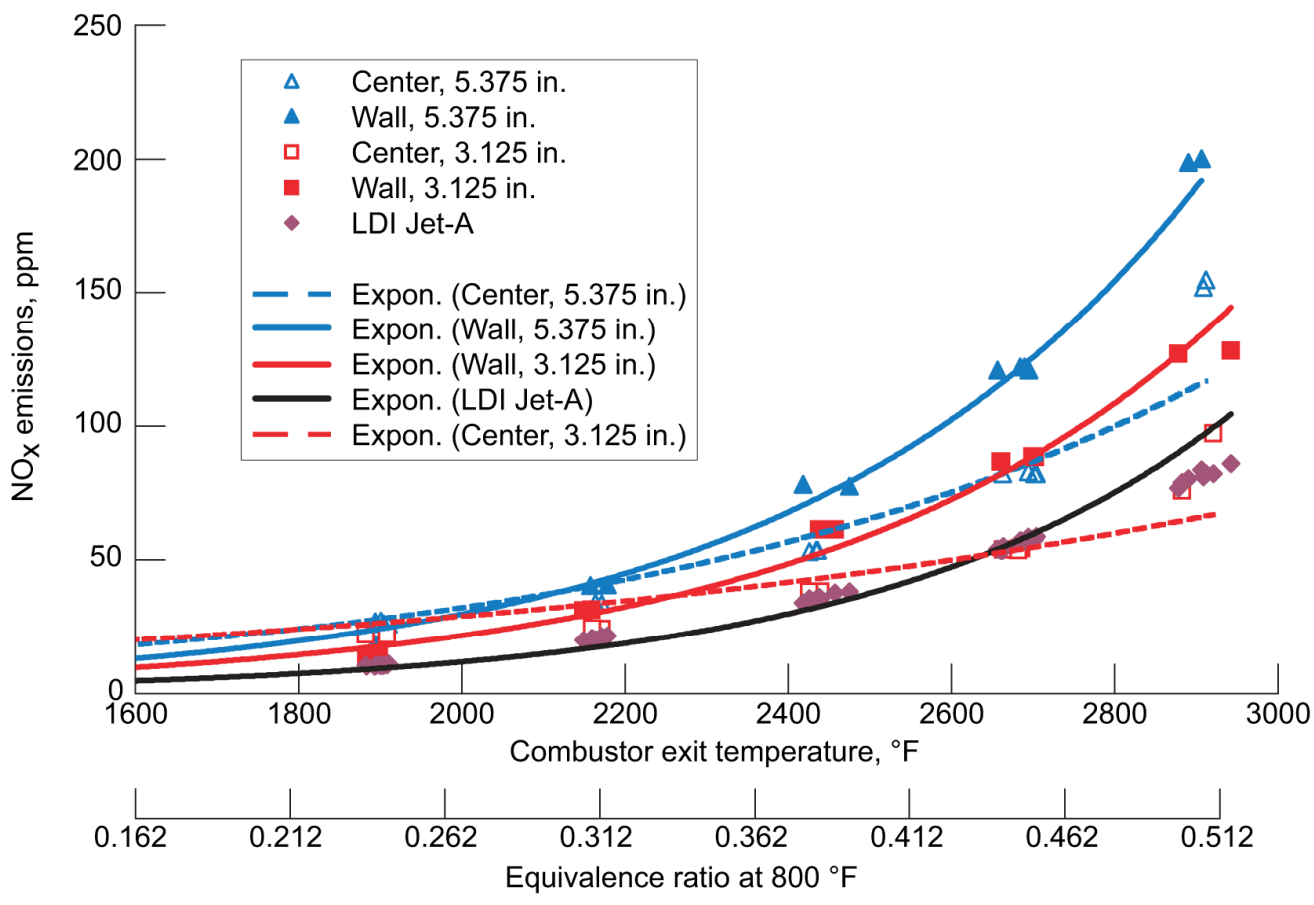

Figure 27. NASA N1, 3.5 in. liner. $P=150$ psia, $T_{3}=800^{\circ} \mathrm{F}, V_{\text {ref }}=60 \mathrm{ft} / \mathrm{s}$.

\section{Data Correlations}

Data correlations were derived for each configuration with a fixed geometry in order to reduce the number of independent variables. All of the configurations were tested over the full range of equivalence ratios $(0.2$ to 0.48$)$. The ranges of the other variables vary somewhat as follows:

Range

\begin{tabular}{|l|l|l|l|}
\hline Configuration & $P_{3}(\mathrm{psia})$ & $T_{3}\left({ }^{\circ} \mathrm{F}\right)$ & $V_{\text {ref }}(\mathrm{ft} / \mathrm{s})$ \\
\hline NASA N1-2.5 in diameter & $100-150$ & $600-1000$ & $100-150$ \\
\hline Configuration C1 & 100 & $630-830$ & $100-140$ \\
\hline Configuration C2 & $70-130$ & $600-620$ & $100-170$ \\
\hline Configuration C3 & 100 & $600-1000$ & $65-100$ \\
\hline Configuration C4 & $100-150$ & $600-985$ & 60 \\
\hline NASA1-3.5 in diameter & $100-200$ & $600-800$ & 60 \\
\hline
\end{tabular}

\section{A. Correlations}

The Eq. (12) is of the same form (exponential) as the LDI Jet-A Eq. (6), but it allows for different coefficients to account for a different fuel and for differences in configurations.

$$
\operatorname{ppm}_{\mathrm{NO}_{\mathrm{x}}}=A^{*} P_{3}{ }^{a} *\left(\phi_{\mathrm{H}_{2}}\right)^{b} *(\tau)^{c} * \exp \left(\frac{T_{3}}{d}\right) *(\Delta P / P)^{e}
$$

\begin{tabular}{|l|c|c|c|c|c|c|c|}
\hline Configuration & $A$ & $a$ & $b$ & $c$ & $d$ & $e$ & $R^{2}$ \\
\hline NASA N1-2.5 in diameter & $8.05 \mathrm{E}-6$ & 2.98 & 1.15 & 0.579 & 645 & 0.658 & 0.73 \\
\hline Configuration C1 & 8.638 & 0. & 1.95 & 0.337 & -794 & 1.45 & 0.34 \\
\hline Configuration C2 & 0.137 & 2.37 & 1.86 & 0.532 & -127 & 0.496 & 0.31 \\
\hline Configuration C3 & 101.0 & 0. & 2.99 & 0.439 & 547 & 0.165 & 0.76 \\
\hline Configuration C4 & 9.355 & 0.275 & 4.12 & 0.455 & 211 & -0.288 & 0.89 \\
\hline NASA N1-3.5 in diameter & 6.208 & 0.469 & 2.27 & 0.645 & 280 & -0.676 & 0.76 \\
\hline NASA N1-3.5 in diameter- $\mathrm{O}_{2}$ & 4.562 & 0.522 & 1.81 & 0.195 & 264 & -0.860 & 0.83 \\
\hline LDI JetA/ $\mathrm{H}_{2}$ & 7.82 & 0.594 & 2.67 & 0. & 350 & -0.56 & Eq. $(5)$ \\
\hline Well Stirred Reactor WSR & 86.47 & 0.343 & 9.21 & 1.19 & 230. & 0. & 0.94 \\
\hline WSR followed by Plug Flow & 57.7 & 0.351 & 9.09 & 0.258 & 213. & 0. & 0.99 \\
\hline
\end{tabular}


The units used in the correlations are $P_{3}$ psia, $\tau$-milliseconds, $T_{3}{ }^{\circ} \mathrm{F} . X$ downstream distance from injector face in inches. The residence time $\tau$ was computed at the combustor conditions.

$$
\tau=\frac{X / 12 .}{V_{\text {ref }}} *\left(\frac{T_{3}}{T_{4}}\right) * 1000 \text { milliseconds }
$$

The exponents are as expected, except for the temperature coefficients (d) of configurations $\mathrm{C} 1$ and $\mathrm{C} 2$ which are negative, probably because of failure of the configuration. Also since configuration $\mathrm{C} 1$ failed, we could not test over the complete pressure range and obtain a pressure coefficient for it, hence a value of zero is inserted in the table. The values of the correlation coefficient $R^{2}$ is low because all of the data was used in the regression without selection so there was more scatter in the correlation.

Obviously if a residence time $\tau$ of $0.5 \mathrm{msec}$ were substituted into the correlations, the hydrogen $\mathrm{NO}_{\mathrm{x}}$ values would be much lower than the LDI Jet-A correlation as shown in the experimental data. Figs. 28 and 29.

The chemical kinetics used for the perfectly stirred reactor PSR (or called here as a well stirred reactor WSR) and the well stirred reactor followed by a plug flow reactor (WSR-PFR) were from Ref. 19. Note the approach of the experimental values to the WSR curves at higher equivalence ratios. This is probably results from the fact that the hydrogen fuel jets are being used for mixing of the gases. In Fig. 30, the logarithm of the $\mathrm{NO}_{\mathrm{x}}$ is plotted versus the equivalence ratio to provide a wider spread of the data at low equivalence ratio. Configuration $\mathrm{C} 1$ and $\mathrm{C} 2$ achieved levels below the well stirred reactor WSR computations. The $\mathrm{NO}_{\mathrm{x}}$ emissions from the configuration of a small WSR $(0.25 \mathrm{msec})$ followed by a plug flow reactor PFR $(1.75 \mathrm{msec})$ were also computed. The WSR-PFR combination was almost an order of magnitude below the WSR calculation. These data are a strong function of time (axial distance) indicating the small mixing scale of the LDI injectors. In comparison to the hydrogen premixed data of Anderson (Ref. 5) who showed that for his configuration $\mathrm{NO}_{\mathrm{x}}$ was not dependent on time. Reference 5 data had blockage levels of $92 \%$ which probably created larger scale mixing smearing the axial (time) effect. The small radial jets in the LDI injectors create rapid mixing of fuel, air and combustion products (high temperature-radical $(\mathrm{OH}, \mathrm{H}, \mathrm{O}$, etc.) containing gas) producing very fast burning rates. The small scale mixing of the LDI geometry probably results in a small WSR at the injector plane.

The functions are complicated and plotting the results at different conditions would show a different comparison. For instance using a residence time $\tau$ of $0.5 \mathrm{msec}$ with hydrogen would result in very low nitrogen oxide levels. The levels at high equivalence ratio approaches the well stirred reactor results, maybe indicating that the higher fuel flow provides for more complete and better mixing with the air.

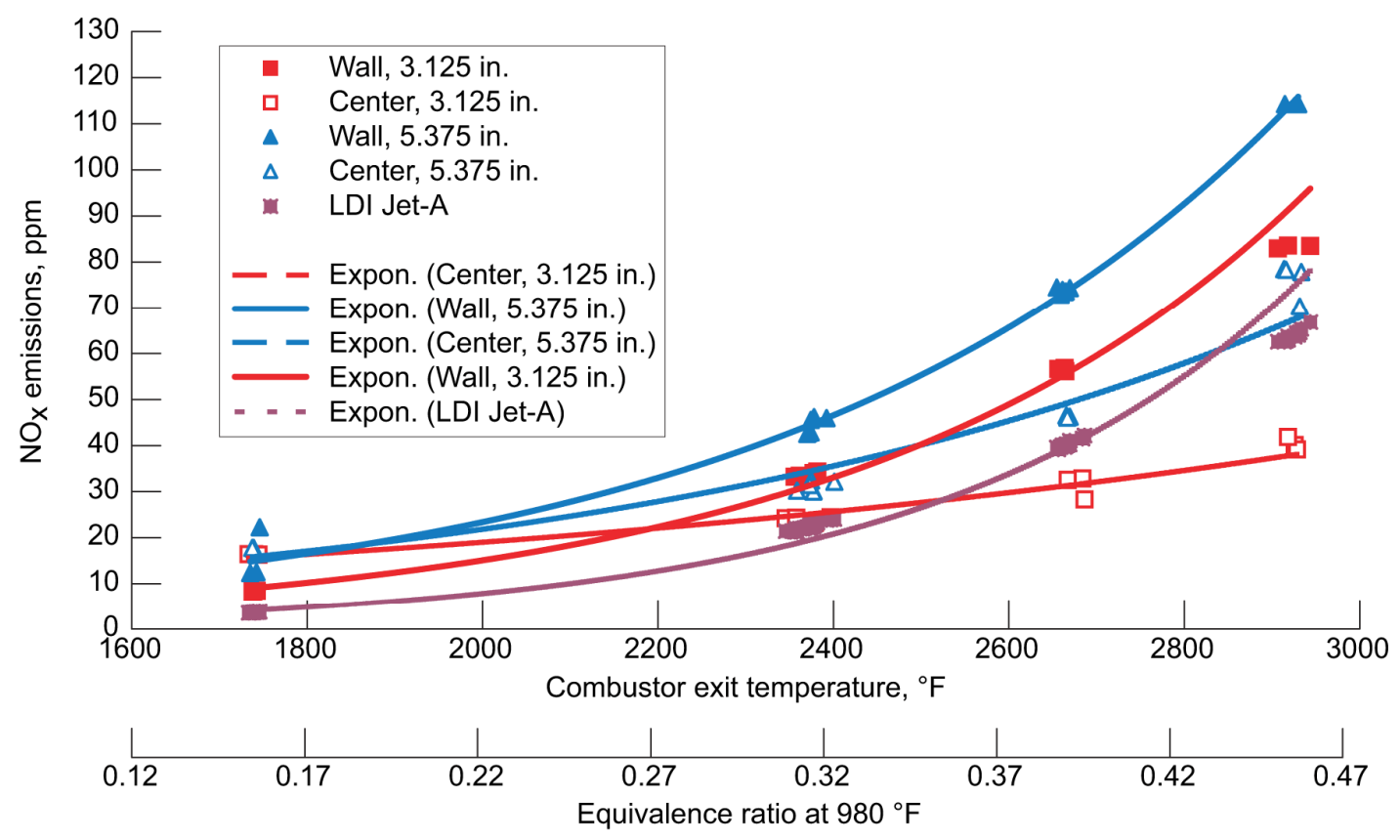

Figure 28. NASA N1, 3.5 in. liner. $P=100 \mathrm{psia}, \mathrm{T}_{3}=980^{\circ} \mathrm{F}, \mathrm{V}_{\mathrm{ref}}=60 \mathrm{ft} / \mathrm{s}$. 

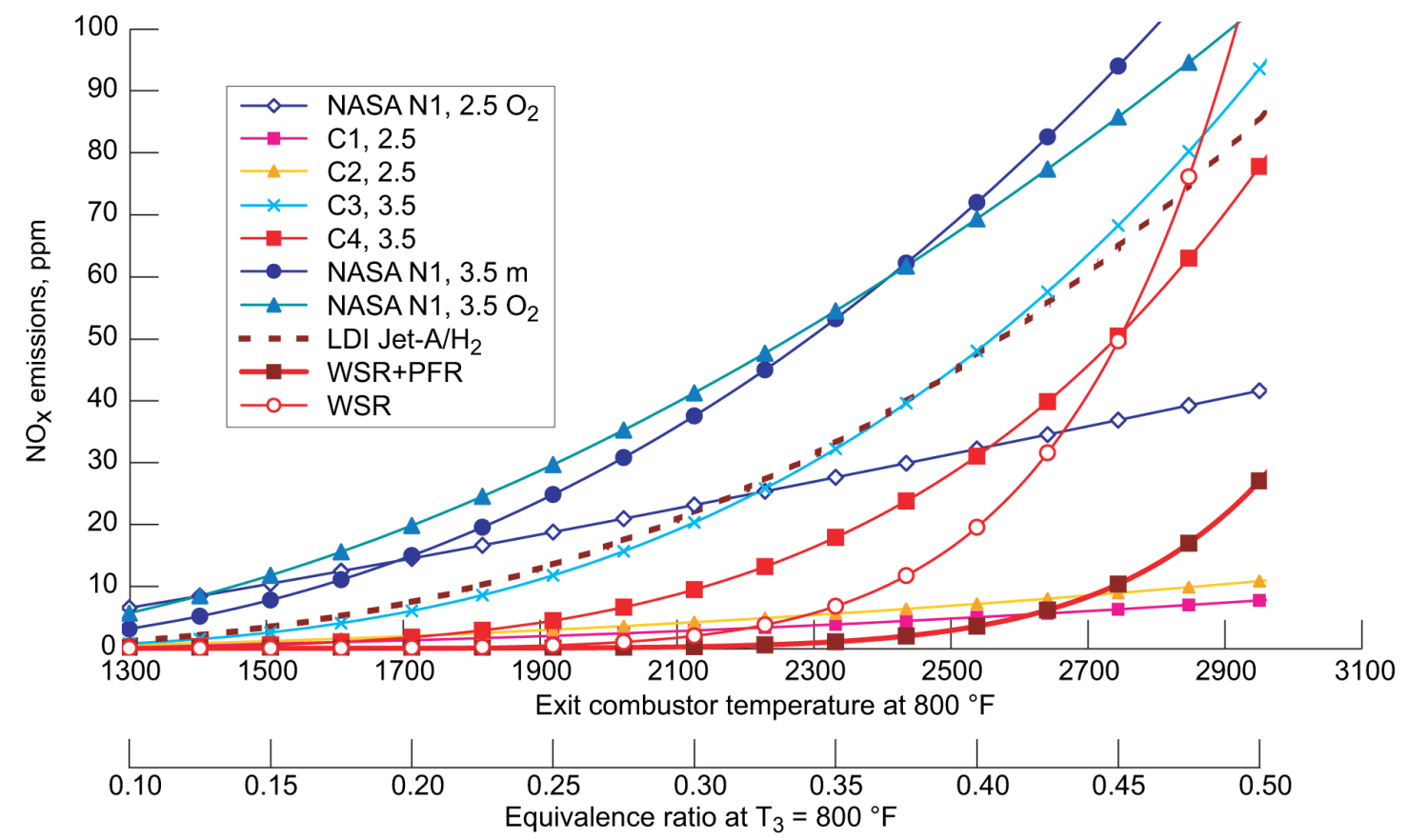

Figure 29. $\mathrm{NO}_{x} \mathrm{ppm}$ for all configurations. $\mathrm{P}_{3}=100 \mathrm{psia}, \mathrm{T}_{3}=800^{\circ} \mathrm{F}, \tau=2 \mathrm{~ms}, \Delta \mathrm{P} / \mathrm{P}=4 \%$.

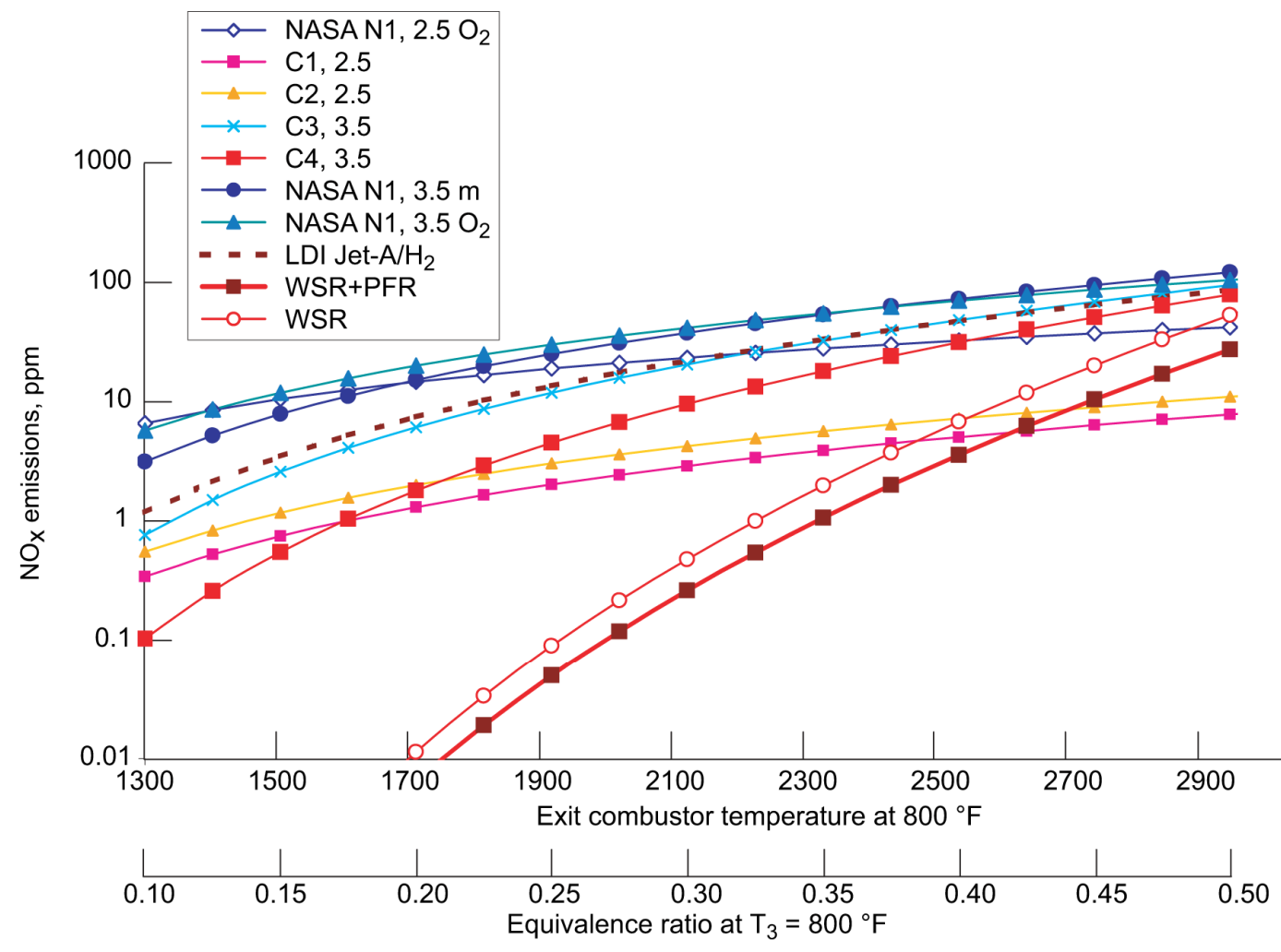

Figure 30. $\mathrm{NO}_{x}$ ppm for all configurations. $\mathrm{P}_{3}=100 \mathrm{psia}, \mathrm{T}_{3}=800^{\circ} \mathrm{F}, \tau=2 \mathrm{~ms}, \Delta \mathrm{P} / \mathrm{P}=4 \%$. 


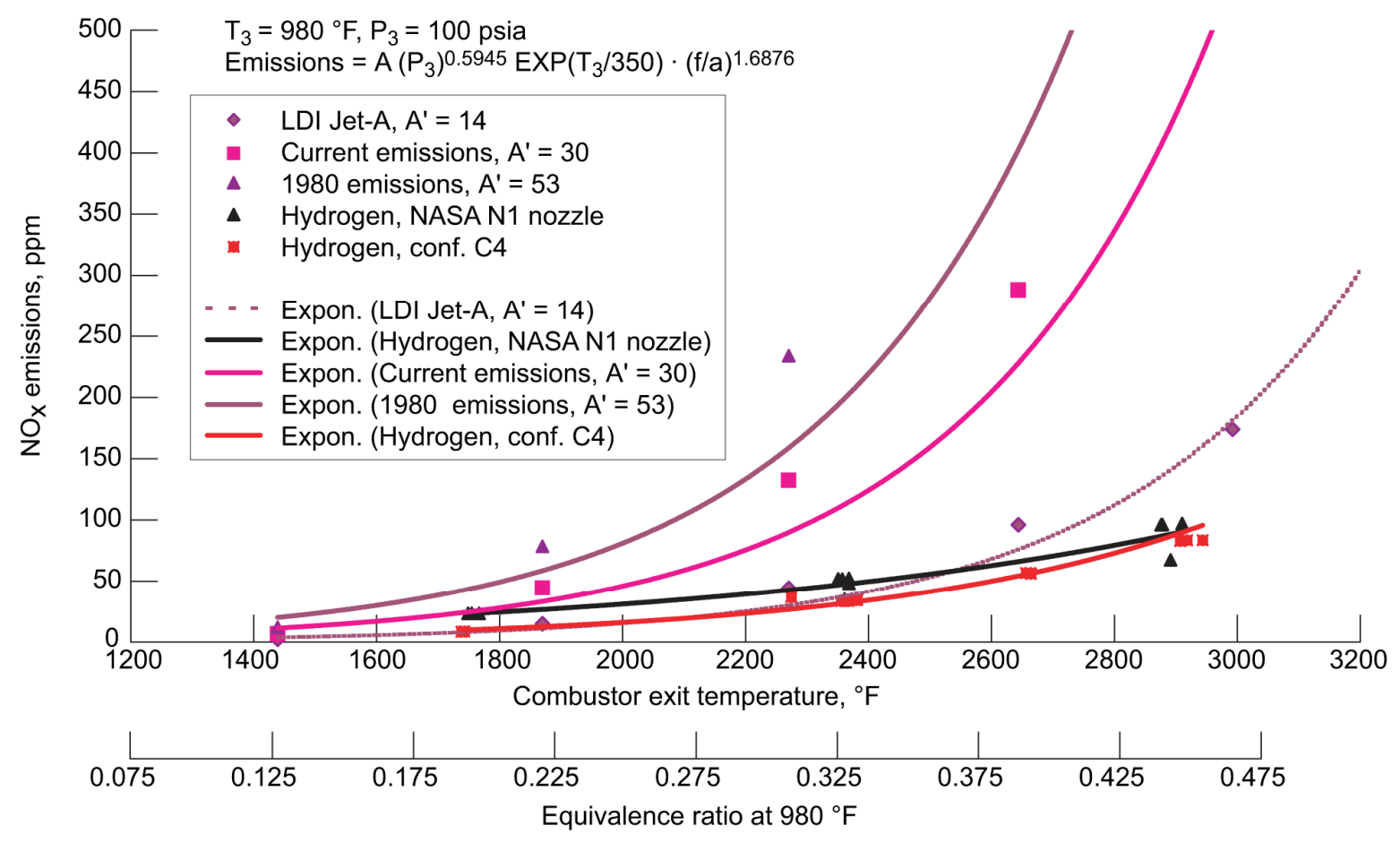

Figure 31. Comparison of emissions, using correlation equation.

\section{B. Progress in Lowering the Emissions and Comparison for Hydrogen}

The $\mathrm{NO}_{\mathrm{x}}$ performance of several combustors in Figs. 30 and 31 were plotted.

To demonstrate the advances that have been made in emissions data from reference ${ }^{18}$ was inclued by curve fitting the data with Eq. (6) and obtaining values of $A^{\prime}$. In Figs. 30 and 31, one set of conditions $(2 \mathrm{msec})$ was chosen to compare the configurations.

Significant progress has been made over the last twenty years on $\mathrm{NO}_{\mathrm{x}}$ emission reductions. The LDI hydrogen combustors compare well with the LDI Jet-A combustors.

\section{Summary}

Several designs were tested. All of the LDI configurations performed well and were very stable. All of the lean direct injectors LDI configurations did result in low levels of nitrogen oxides $\mathrm{NO}_{\mathrm{x}}$. No flashback or autoignition phenomena were encountered. Configuration $\mathrm{C} 4$ performed the best from a low $\mathrm{NO}_{\mathrm{x}}$ and durability criteria. The more injection points resulted in a lower level of $\mathrm{NO}_{\mathrm{x}}$, but without advanced manufacturing techniques, the injectors might be more difficult to construct. Cooling can be a problem with hydrogen combustors, and two of the configurations failed during testing.

These were our first tests for using lean direct injection LDI concepts with hydrogen. These designs were "out of the box" testing and did not have a significant amount of optimization. Funding limited the amount of optimization that could occur. However, even with those limits the results showed significant progress and demonstrated low $\mathrm{NO}_{\mathrm{x}}$. It is the authors' opinion that with additional modeling and optimization significant improvements can still be made beyond the current effort.

\section{Appendix- $\mathrm{NO}_{\mathrm{x}}$ ppm Corrected to $15 \%$ Oxygen}

Some references report the $\mathrm{NO}_{\mathrm{x}}$ ppm data corrected to $15 \%$ oxygen. Nitrogen oxide emissions from ground power and ground transportation vehicles are typically correct to $15 \%$ dry oxygen, so for comparison with our data we show calculations on the $\mathrm{NO}_{\mathrm{x}}$ corrected data. However, this practice is not commonly done for aircraft gas turbine combustors. In order to compare configurations reported at both values it is important to be able to correct the $\mathrm{NO}_{\mathrm{x}}$. Lefebvre ${ }^{4}$ gives the simple correction equation as 


$$
N O_{x_{c o r}}=N O_{x 15 \% O_{2}} / N O_{x m e a s u r e d}=\frac{5.9}{\left(20.9-100 * O_{2}\right)}
$$

This equation does not include the ffect of changes in combustor conditions with equivalence ration, only the effect of dilution, for example from cooling or quench air. $\mathrm{The}^{\mathrm{NO}}$ xcor is plotted versus equivalence ration using Eq. (9) and A1 in the figure below.

Figure $\mathrm{A} 1 . \mathrm{NO}_{\mathrm{x}}$ corrected versus hydrogen equivalence ration at an equivalence ration of 0.33 there is no correction. At low equivalence ratio there can be a large positive increase and at high equivalence ration the $\mathrm{NO}_{\mathrm{x}}$ is reduced.

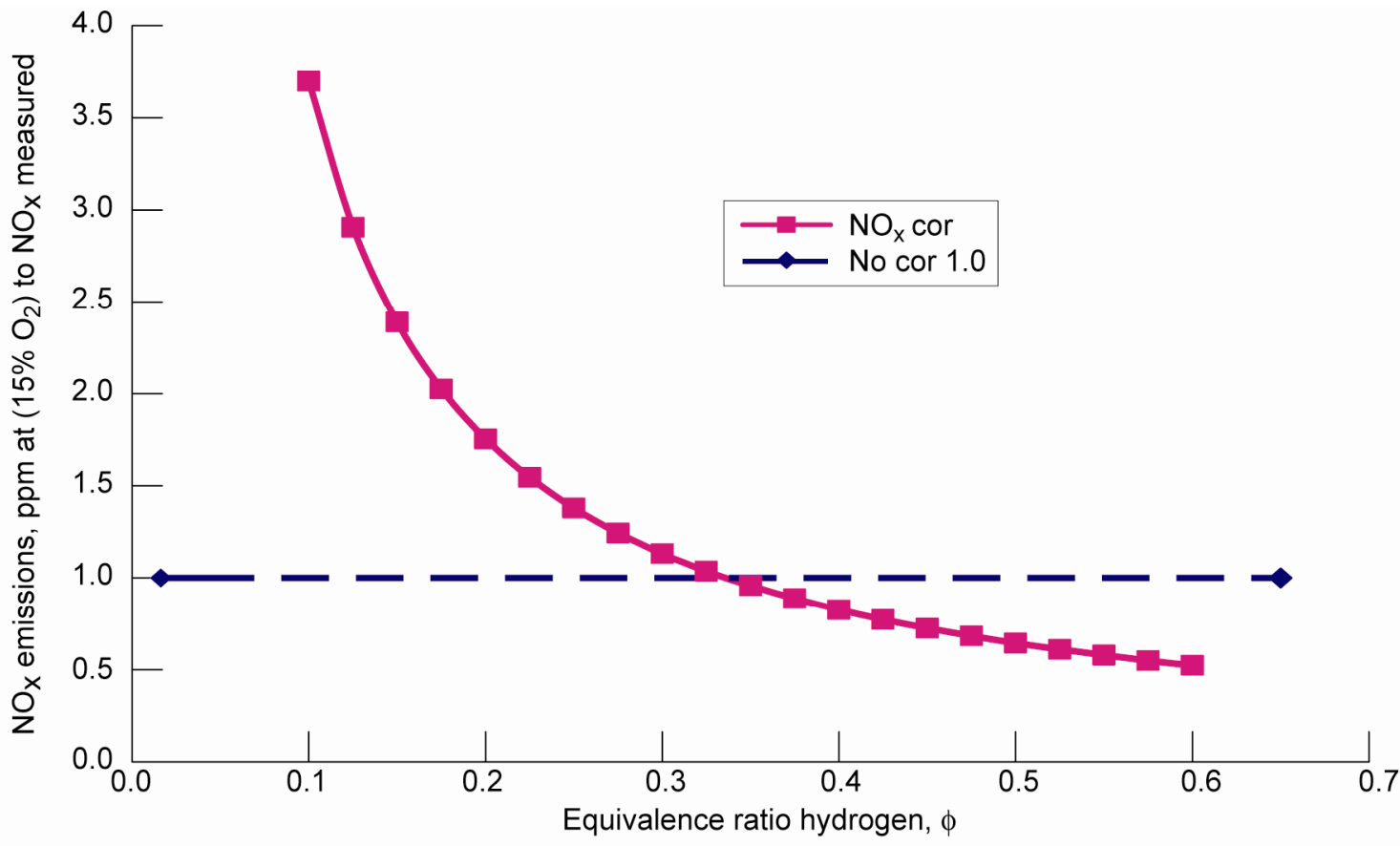

Figure $\mathrm{A} 1 . \mathrm{NO}_{\mathrm{x}}$ corrected to $15 \%-\mathrm{O}_{2}$ vs equivalence ratio.

\section{Acknowledgments}

The authors would like to gratefully acknowledge the excellent support of the RCL cell23 team: James A. Mullins, William Vaccariello, Sylvestor Legarth, Robert Shaw, Doug Bewley, Jim Little, Dawn Sgro, Robert Tornabene, Gregory Lung, Bruce Frankenfield, and Jerri Vokac.

\section{References}

${ }^{1}$ Brewer, G.D.: "Hydrogen Aircraft Technology," CRC Press, 1991.

${ }^{2}$ Sloop, J.L.: "Liquid Hydrogen as a Propulsion Fuel, 1945-1959,” NASA SP-4404, 1978.

${ }^{3}$ Zeldovich, Y.B. The Oxidation of Nitrogen in Combustion and Explosions. Acta Physicochimica URSS 21. pp. 577-628, 1946.

${ }^{4}$ Lefebvre, A.H. Gas Turbine Combustion, Second Edition. Taylor \& Francis, 1999.

${ }^{5}$ Anderson, D.N.: Emissions of Oxides of Nitrogen from an Experimental Pre-mixed Hydrogen Burner. NASA TMX-3393, 1976.

${ }^{6}$ Dahl, G.; Suttrop, F.: Engine Control and Low-NO ${ }_{\mathrm{x}}$ Combustion for Hydrogen Fuelled Aircraft Gas Turbines. Int. J. Hydrogen Energy, Vol. 23, No. 8, pp 695-704, 1998.

${ }^{7}$ Klug, H.G. The Cryoplane Project-Aircraft Using Cryogenic Fuel and Their Impact on the Atmosphere, XVIII General Assembly, European Geophysical Society, 1993. 
${ }^{8}$ Ziemann, J.; Shum, F.; Moore, M.; Kluyskens, D.; Thomaier, D.; Zarzalis, N.; and Eberius, H.: Lox-NO ${ }_{x}$ Combustors for Hydrogen Fueled Aero Engines. Hydrogen Energy Progress XI, Proceedings of the 11th World Hydrogen Energy Conference, Vol II, pp. 1787-1798. June 23-28, 1996.

${ }^{9}$ Brand, J; Sampath, S.; Shum, F.; Bayt, R.L.; and Cohen, J.: "Potential Use of Hydrogen in Air Propulsion," AIAA/ICAS International Air \& Space Symposium and Exposition, Dayton, OH. AIAA-2003-2879, July 2003.

${ }^{10}$ Moder, Jeffery, et al., "National Combustion Code: User Guide." NASA Glenn Research Center at Lewis Field, March 5, 2002.

${ }^{11}$ Shih, T.-H.; Norris; A.; Iannetti, A.; Marek, C.J.; Smith, T.D.; Liu, N.-S.; Povinelli, L.A., "A Study of Hydrogen/Air Combustor Using NCC." AIAA-2001-0808, 39th AIAA Aerospace Sciences Meeting \& Exhibit, 8-11 January 2001/Reno, NV.

${ }^{12}$ Shih, T.-H.; Smith, T.D.; Marek, C.J.; Iannetti, A.; Norris; A.; Liu, N.-S., Numerical Studies of a Single Hydrogen/Air Gas Turbine Fuel Nozzle, 33rd AIAA Fluid Dynamics Conference \& Exhibit June 2003, AIAA-2003-4249.

${ }^{13}$ Schefer, R.W.; Smith, T.D.; and Marek, C.J.: "Evaluation of NASA Lean Premixed Hydrogen Burner" Sandia National Laboratory, SAND2002-8609, January 2003.

${ }^{14}$ Bianco, Jean: NASA Lewis Research Center's Combustor Test Facilities and Capabilities. NASA TM-106903 (AIAA Paper 95-2681), 1995.

${ }^{15}$ Little, James E., Nemets, Stephen A., Tornabene, Robert T., Smith, Timothy D., Frankenfield, Bruce J., Manning, Stephen D., and Thompson, William K., Fuel-Flexible Gas Turbine Turbine Combustor, NASA/TM-2004-212715.

${ }^{16}$ Holdeman, J.D., Smith, T.D., Clisset, J.R., and Lear, W.E., A spreadsheet for the Mixing of a Row of Jets with a Confined Crossflow. NASA/TM-2005-213137.

${ }^{17}$ Tacina, Robert, Wey, Changlie, Liang, Peter, and Mansour, Adel, A Low $\mathrm{NO}_{\mathrm{x}}$ Lean-Direct Injection, Multipoint Integrated Module Combustor Concept for Advanced Aircraft Gas Turbines, Clean Air Conference, Porto, Portugul, NASA/TM-2002-2111347.

${ }^{18}$ Tacina, Robert R., Combustor Technology for Future Aircraft, NASA TM-103268, 26th Joint Propulsion Conference, Orlando, Florida, July 16-18, 1990, AIAA-90-2400

${ }^{19}$ Miller, J.A., and Bowman, C.T., Mechanism and Modeling of Nitrogen Chemistry in Combustion, Progress in Energy and Combustion Science, Vol. 15, p. 287, 1989. 